\title{
Hepatocellular Carcinoma: State of the Art Imaging and Recent Advances
}

\author{
Patrick J. Navin and Sudhakar K. Venkatesh* \\ Department of Radiology, Mayo Clinic, Rochester, MN, USA
}

\begin{abstract}
The incidence of hepatocellular carcinoma (HCC) is increasing, with this trend expected to continue to the year 2030. Hepatocarcinogenesis follows a predictable course, which makes adequate identification and surveillance of at-risk individuals central to a successful outcome. Moreover, imaging is central to this surveillance, and ultimately to diagnosis and management. Many liver study groups throughout Asia, North America and Europe advocate a surveillance program for atrisk individuals to allow early identification of HCC. Ultrasound is the most commonly utilized imaging modality. Many societies offer guidelines on how to diagnose HCC. The Liver Image Reporting and Data System (LIRADS) was introduced to standardize the acquisition, interpretation, reporting and data collection of HCC cases. The LIRADS advocates diagnosis using multiphase computed tomography or magnetic resonance imaging (MRI) imaging. The 2017 version also introduces contrast-enhanced ultrasound as a novel approach to diagnosis. Indeed, imaging techniques have evolved to improve diagnostic accuracy and characterization of HCC lesions. Newer techniques, such as T1 mapping, intravoxel incoherent motion analysis and textural analysis, assess specific characteristics that may help grade the tumor and guide management, allowing for a more personalized approach to patient care. This review aims to analyze the utility of imaging in the surveillance and diagnosis of HCC and to assess novel techniques which may increase the accuracy of imaging and determine optimal treatment strategies.
\end{abstract}

Citation of this article: Navin PJ, Venkatesh SK. Hepatocellular carcinoma: State of the art imaging and recent advances. J Clin Transl Hepatol 2019;7(1):72-85. doi: 10.14218/JCTH.2018.00032.

\section{Introduction}

Incidence rates of hepatocellular carcinoma (HCC) in the USA have tripled in the previous three decades, with future

Keywords: Hepatocellular carcinoma; CT; MRI; Ultrasound; Advances. Abbreviations: AASLD, American Association for the Study of Liver Diseases; CEUS, contrast-enhanced ultrasound; CT, computed tomography; FDG, fluorodeoxyglucose; HCC, hepatocellular carcinoma; IVIM, intravoxel incoherent motion imaging; LIRADS, Liver Imaging Reporting and Data System; MRI, magnetic resonance imaging; MRS, magnetic resonance spectroscopy; NAFLD, nonalcoholic fatty liver disease; NASH, non-alcoholic steatohepatitis; PET, positron emission tomography; TACE, transarterial chemoembolization.

Received: 4 May 2018; Revised: 31 December 2018; Accepted: 4 January 2019 *Correspondence to: Sudhakar K. Venkatesh, Mayo Clinic, Rochester, $2001^{\text {st }}$ Street, Rochester MN 55905, USA. Tel: +1-507-284-1728, Fax: +1-507-2842405, E-mail: venkatesh.sudhakar@mayo.edu projections from the Surveillance, Epidemiology and End Results program indicating continued growth of $\mathrm{HCC}$ incidence to the year 2030.1,2 HCC generally presents late in the disease process and as a result the associated mortality is relatively high, with sources estimating it to be the $3^{\text {rd }}$ or $4^{\text {th }}$ most common cause of death due to cancer worldwide. ${ }^{1,3,4}$ Five-year survival is $<16 \%$, however when identified at an earlier stage the 5-year survival rates have been as high as $93 \% .^{5,6}$ The aim of this review is to evaluate how imaging plays a part in the surveillance and diagnosis of HCC and to assess novel techniques which may increase the accuracy of imaging and determine optimal treatment strategies.

\section{Carcinogenesis}

HCCs typically arise in patients with chronic liver disease. Cirrhosis may or may not be present. The development of HCC is complex, with multiple steps known as 'hepatocarcinogenesis' and dictated by progressive genetic alterations. ${ }^{7}$ Emerging research suggests intrahepatic stem cells as the likely cell of origin, as opposed to dedifferentiation of a hepatocyte. $^{8}$

Regenerative nodules are the first step, consisting of rounded regions of hepatic parenchyma, surrounded by fibrosis. ${ }^{9}$ Smaller regenerative nodules are generally not discernable on standard imaging and are benign entities. Dysplastic foci and ultimately dysplastic nodules then develop within these regenerative nodules or hepatic lobules in noncirrhotic livers. Dysplastic nodules are composed of hepatocytes with precancerous changes, which ultimately develop to form HCC. Angiogenesis first occurs in dysplastic nodules, with the formation of unpaired arteries. This arterial supply increases from this stage through hepatocarcinogenesis and accounts for the arterial phase hyperenhancement associated with $\mathrm{HCC}$ on imaging. ${ }^{10}$

Stromal invasion is the predominant feature to differentiate HCC from dysplastic nodule, with tumor cells invading into the surrounding fibrous tissue. ${ }^{11}$ The earliest form is analogous to a "carcinoma in situ" seen elsewhere in the body and is described as 'early HCC'. It replaces instead of displaces the hepatic parenchyma. Early HCCs are precursors

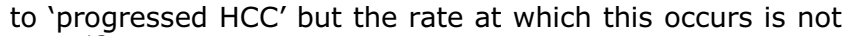
clear. ${ }^{12}$ Progressed HCCs demonstrate greater ability for vascular invasion and metastatic spread with displacement of the hepatic parenchyma. Increased size generally indicates higher grade, with larger masses $(>2 \mathrm{~cm}$ ) demonstrating heterogeneity with mosaic architecture and areas of necrosis or hemorrhage. ${ }^{13}$ Higher grade lesions characteristically demonstrate vascular, biliary and tumor capsule invasion, increasing the risk for extrahepatic spread. ${ }^{14,15}$ Most common 
extrahepatic sites for metastases include the lung, abdominal lymph nodes and bone. ${ }^{16}$

\section{Risk factors}

Estimation of risk is required before patients can be stratified into specific surveillance programs. There are several factors associated with increasing risk of $\mathrm{HCC}$, including geographical, ethnic, infectious and environmental considerations.

The incidence of HCC is highest in eastern and southeastern Asia and northern and western Africa, with incidence rates $>15 / 100,000 .{ }^{17}$ The risk factors most commonly implicated include cirrhosis, hepatitis $B$ and hepatitis $C$. The risk is independent of cause, with an incidence of $1-8 \%$ among individuals with compensated cirrhosis and $1 \%$ in individuals with chronic hepatitis. ${ }^{18,19}$ For $20-56 \%$ of individuals, however, the diagnosis of HCC in cirrhotic livers is the first presentation of cirrhosis. ${ }^{20,21}$

Viral hepatitis, predominantly hepatitis B and C, are thought to account for $>50 \%$ of cases of $\mathrm{HCC}^{4}$ The hepatitis $B$ virus affects approximately $3.2 \%$ of people worldwide, ${ }^{22}$ while hepatitis $C$ virus accounts for approximately one-third of cases of HCC in the USA. ${ }^{23}$ Environmental and ingested toxins demonstrate variable roles in increasing the incidence of HCC in various parts of the world. Alcohol has a demonstrated dose-effect relationship with the development of HCC. ${ }^{24}$ Genetic and metabolic conditions, in the form of hereditary hemochromatosis, obesity, gallstone disease, type 2 diabetes mellitus, alpha- 1 antitrypsin deficiency, acute intermittent porphyria and non-alcoholic fatty liver disease (NAFLD), also have demonstrated effect on increased risk of HCC. ${ }^{25-31}$

NAFLD is emerging as one of the most common causes of chronic liver disease and is thought to become one of the leading causes for liver transplant. ${ }^{32,33}$ NAFLD occurs along a spectrum, ranging from steatosis to non-alcoholic steatohepatitis (commonly known as NASH) and finally cirrhosis. $\mathrm{NASH}$ is a known risk factor for HCC. ${ }^{34,35} \mathrm{NASH}$ may also progress to cirrhosis, with increased risk of HCC; however, HCC can occur in NAFLD patients in the absence of advanced fibrosis or cirrhosis. ${ }^{36,37}$ It has been estimated that $4-22 \%$ of HCC occurs in the setting of NAFLD.

\section{Surveillance}

Multiple liver study groups have proposed surveillance programs for at-risk groups to detect HCC at an earlier stage. ${ }^{38-44}$ Despite the worldwide utilization of surveillance programs, their validity, in survival terms, have yet to be conclusively verified. A recent meta-analysis assessed the effect of HCC surveillance on overall survival as well as other endpoints. The researchers found a prolonged survival with odds ratio of 1.9 (confidence interval: 1.67-2.17). Although they allow for lead-time bias, the method of surveillance varied within the meta-analysis. ${ }^{45}$

The major liver study groups advise use of ultrasound, with or without serum alpha-fetoprotein, for surveillance. The American Association for the Study of Liver Diseases (AASLD) advises ultrasound surveillance. ${ }^{38}$ This is based on a previous Chinese study that demonstrated a reduction in mortality of $37 \%$ with this program and on a more recent Taiwanese study demonstrating a reduction in mortality of $31 \% .{ }^{46,47}$ The European societies utilize ultrasound surveillance only, ${ }^{39,40}$ with other USA and Asian groups advising the use of ultrasound with alpha-fetoprotein as a biomarker. ${ }^{41-44}$ When a lesion is identified on ultrasound, size dictates future management; however, there is no universally agreed-upon approach.

In lesions $<1 \mathrm{~cm}$, the AASLD, Liver Imaging Reporting and Data System (LIRADS), National Comprehensive Cancer Network and European Association for the study of the Liver - European Organization for the Research and Treatment of Cancer recommend repeat ultrasound at 3- to 6-month intervals. ${ }^{38,39,43,48}$ In lesions $>1 \mathrm{~cm}$, the AASLD recommends multiphase CT or magnetic resonance imaging (MRI) imaging. The Japanese Society of Hepatology recommends multiphase CT or MRI when a nodule of any size is detected.

\section{Diagnosis}

HCC is a unique malignancy in that it can be diagnosed based on imaging findings alone, as is the recommended approach by major societies on liver studies. Histological confirmation with biopsy is avoided due to inherent risks of invasive biopsy and a small but definite risk of needle track seeding. The imaging characteristics of arterial phase hyperenhancement with washout on portal venous and delayed sequence and enhancing capsule is the classic imaging appearance (Supplementary Fig. 1).

On imaging using dynamic contrast studies, the identification and discrimination of hepatocellular cancer from its precursors and other hepatic masses depend on multiple pathophysiological alterations which occur during hepatocarcinogenesis. ${ }^{49}$ The generation of an altered arterial network and disappearance of portal venous flow to the nodule creates the typical arterial phase hyperenhancement and washout in portal venous and delayed phase appearance compared to background liver. The formation of a tumor capsule and fibrous septae are not seen in regenerative nodules, dysplastic nodules, or early HCCs but are seen in $70 \%$ of more progressed HCCs. ${ }^{15}$

Fat content varies throughout hepatocarcinogenesis. Hepatocytes tend to demonstrate higher fat content during early phases as dysplastic nodules or early HCCs. ${ }^{50}$ The presence of diffuse fat in progressed HCCs is uncommon. ${ }^{11,51}$ Iron deposition during this process also varies. Peak iron content occurs in dysplastic nodules and decreases as dedifferentiation progresses and is rarely seen in early and progressed HCCs. ${ }^{52}$ Organic anionic transporting polypeptides (OATPs) are involved in the transport of bile salts and many other substrates into the hepatocytes, including the hepatocytespecific agent gadoxetate disodium (Gd-EOB-DTPA). ${ }^{10}$ Expression of these proteins decreases in high-grade dysplastic nodules and also in HCCs which result in decreased uptake of gadoxetate by the dedifferentiated lesions. ${ }^{10,53}$

Many societies offer guidelines on how to diagnose HCC. The American College of Radiology developed LIRADS ${ }^{48}$ to standardize how data concerning HCC is acquired, interpreted and reported. This is supported by a specific lexicon, imaging algorithm, and illustrative atlas. Their guidance is intentionally designed to resemble that of the AASLD. The Organ Procurement and Transplant Network/United Network for Organ Sharing group have also published guidance to aid in interpretation and management (Supplementary Tables $2 \& 3$ ).

As outlined above, once a lesion is identified on non-contrast ultrasound measuring $>1 \mathrm{~cm}$, it is further evaluated with noninvasive diagnostic tests. For all guidelines, this involves multi-row detector CT or contrast-enhanced MRI using an extracellular contrast agent. The decision on whether to use 

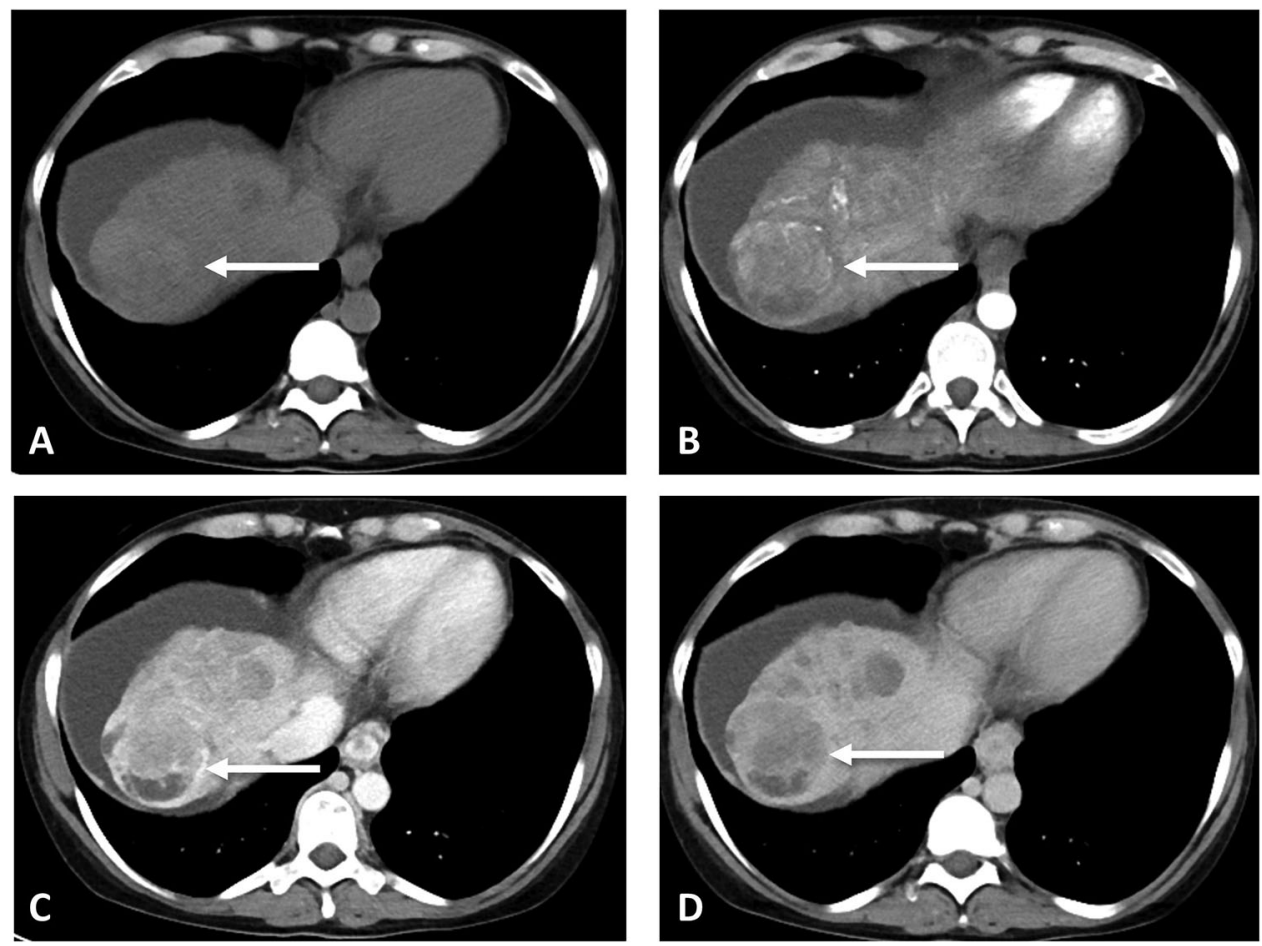

Fig. 1. Axial abdominal computed tomography in a 56-year-old male with alcoholic cirrhosis. Non-contrast enhanced (A), arterial phase (B), portal venous (C) and delayed phase $(D)$ images illustrate multiple masses in the right liver with arterial phase hyperenhancement (arrow) that shows washout and pseudocapsule formation on portal venous phase and delayed imaging.

CT or MRI often depends on local protocol. Studies have demonstrated similar sensitivities between the two modalities, with MRI perhaps demonstrating a slightly higher diagnostic performance. ${ }^{54-57}$ Contrast-enhanced ultrasound (CEUS) is advocated by some societies, namely the Japanese Society of Hepatology, Italian Association for the Study of Liver, the National Comprehensive Cancer Network, LIRADS, the Canadian Association for the Study of Liver and the Asian Pacific Association for the Study of Liver. ${ }^{42,43,58-60}$

The radiological hallmarks of HCC as visualized on CT or MRI are: a) arterial phase hyperenhancement with b) portal venous washout or delayed phase washout. This may be with or without c) enhancing capsule. ${ }^{38,39}$ Pathological diagnosis is generally not recommended unless the lesion remains indeterminate on all available imaging. This is due to the high specificity of available imaging in diagnosing HCC based on typical appearance, which reaches $100 \%$ in some studies. ${ }^{61}$ In contrast, the risk of major complications is $0.05 \%$ with biopsy and the risk of tumor seeding can be as high as $2.7 \% .^{62}$

\section{Cross-sectional imaging}

Multidetector CT is readily available and offers rapid acquisition of high spatial resolution images (Fig. 1). Typical protocols have three phases obtained after injection of intravenous iodinated contrast agent; late arterial phase ( $25-40 \mathrm{~s}$ postinjection), portal venous phase (65-80 s post-injection) and delayed phase (5-10 $\mathrm{m}$ post-injection). The late arterial phase allows for greatest appreciation of the arterial phase hyperenhancement associated with HCC. Subtraction images can also be reconstructed to aid in the detection of enhancement in the various phases. Contrast medium (extracellular contrast medium) is typically of low osmolarity with iodine concentration of $300-350 \mathrm{mg} / \mathrm{mL}$. Injection rates vary from $4-8 \mathrm{~mL} / \mathrm{s}$. In our center, images of all enhancement phases are reconstructed in axial and coronal planes at $3 \mathrm{~mm}$ slice thickness.

A 1.5 or 3 Tesla field strength MR scanner can be utilized. Protocols vary per center; however, a 3D T1-weighted sequence with fat saturation and dynamic contrast enhancement is generally required (Fig. 2). Phases of enhancement are similar to those of CT described above. With the recent revision of LIRADS (LIRADs 2017), other features are recognized as secondary/ancillary for the diagnosis of HCC. ${ }^{48}$ For example, abnormal restricted diffusion and hyperintensity on axial fat saturated T2-weighted sequence ${ }^{48}$ (Fig. 2). The contrast media typically used are gadolinium-based extracellular agents. Hepatobiliary agents that are actively taken up by functioning hepatocytes are increasingly used in many European studies. HCCs are typically seen as hypointense lesions in the hepatobiliary phase, although a well-differentiated HCC can show uptake of hepatobiliary agent occasionally (Fig. 3).

Arterial phase hyperenhancement is deemed the most sensitive feature in the diagnosis of HCC, with figures as high as $96 \% .{ }^{61,63,64}$ It is defined in LIRADS as non-rim-like enhancement in all or part of an observation in the arterial phase that is unequivocally greater than that of the liver. ${ }^{48}$ As this trait is present due to neovascularization, the sensitivity is decreased for early HCC where neovascularization is less well established. ${ }^{65}$ There is also a wide differential associated with arterially enhancing lesions in the liver and therefore the specificity and positive predictive value of this feature is low. ${ }^{64,66}$

"Washout" refers to the progressive reduction in enhancement in later phases of the multiphase study, with a lesion 
Navin P.J. et al: Hepatocellular carcinoma- advances in imaging
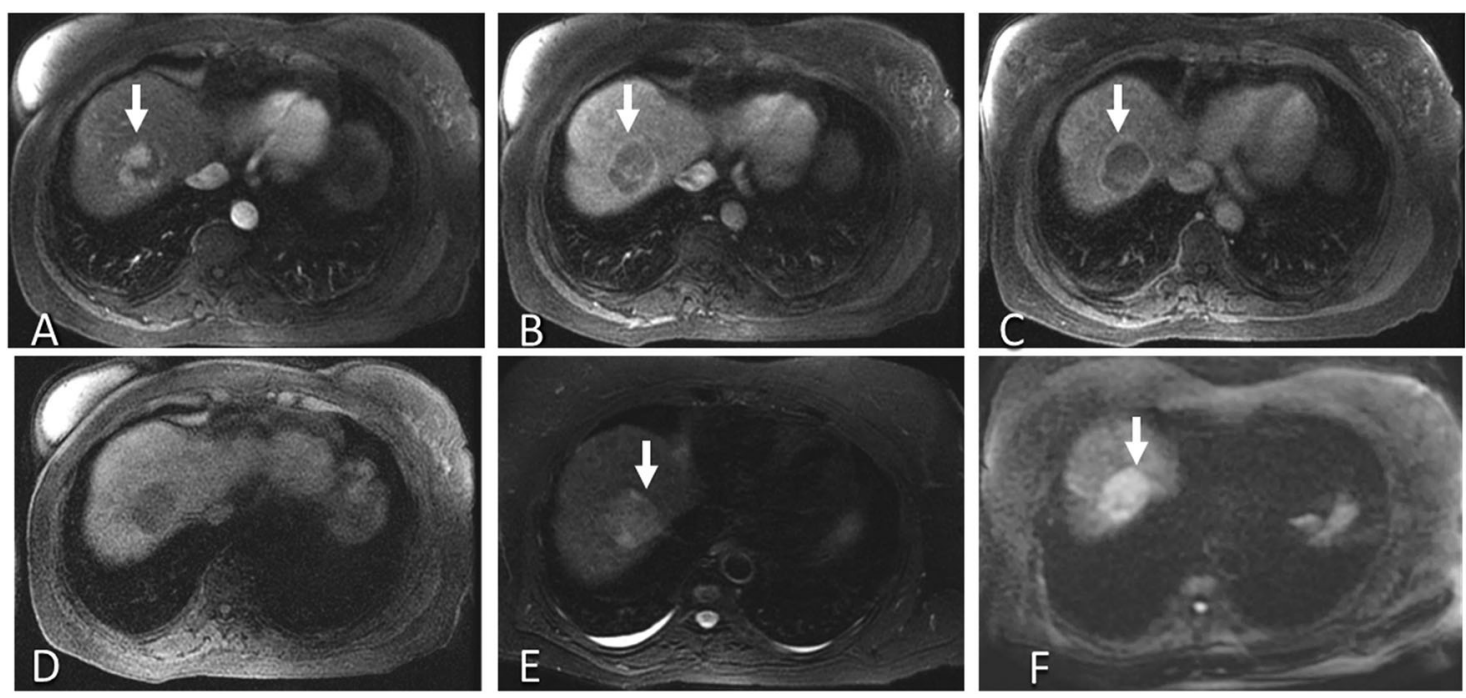

Fig. 2. Axial magnetic resonance imaging of the HCC in a 57-year-old patient with cirrhosis secondary to chronic hepatitis $C$ infection. Arterial ( $A$ ), portal venous (B), delayed (C) phase demonstrating arterial phase hyperenhancement in HCC (arrow) which washes out on portal venous and delayed phases. This mass demonstrates T1 hypointensity (D), and mild T2 hyperintensity $(E)$ with mild restricted diffusion $(F)$.

demonstrating decreased enhancement compared to neighboring liver in portal venous and delayed phases. The sensitivity of "washout" alone has been quoted as $53-79 \%$, with a specificity of $62-100 \%$ in a per-nodule basis. ${ }^{61,63,64}$ The assessment of "washout" however is quite subjective and difficult in cases of established cirrhosis. The use of hepatocyte-specific contrast agents may also add confusion. Hypoenhancement during the transitional phase $(2-5 \mathrm{~m})$ of hepatobiliary agent MRI should not be confused with "washout" associated with HCC. As a result, guidelines such as LIRADS advise for the assessment of "washout" in portal venous phase only when utilizing hepatocyte-specific contrast agents.

The appearance of an enhancing capsule around a lesion in at-risk patients demonstrates a sensitivity of $42-64 \%$ with a specificity of $86-96 \%$ for diagnosing HCC. It is visualized as a

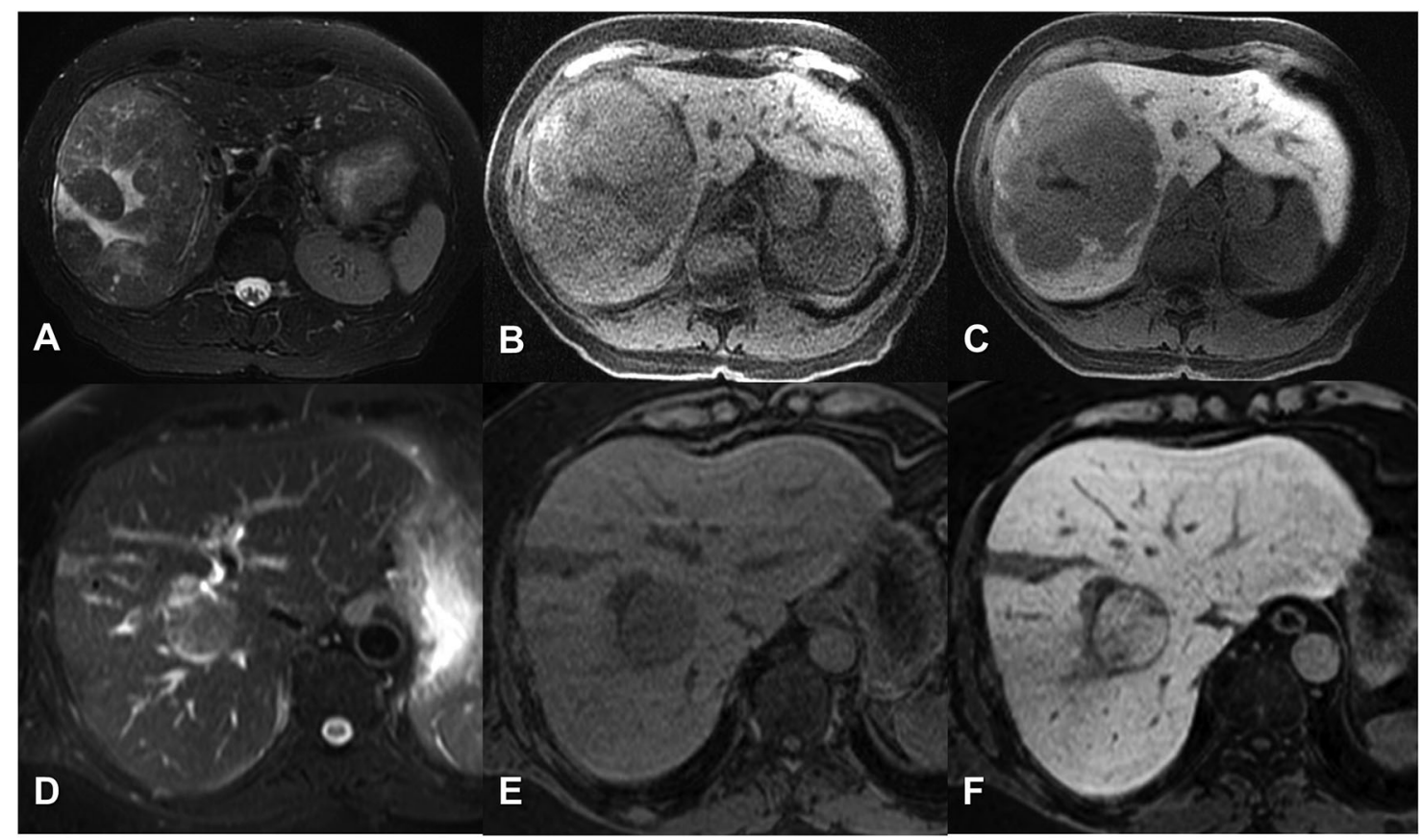

Fig. 3. Axial magnetic resonance imaging on a separate patient performed with hepatobiliary contrast agent (gadoxetate) in two separate patients. Axial T2-weighted (A) and pre-contrast T1-weighted (B) demonstrates a large hepatocellular carcinoma in the right liver with minimal uptake on hepatobiliary phase imaging (C). This contrasts to the second patient with HCC that also shows mild hyperintensity on T2-weighted (D) and hypointensity on T1-weighted (E) but demonstrates uptake of contrast in the hepatobiliary phase (arrow, F). 
defined area of enhancement around a lesion in portal venous or delayed imaging. This may represent a true capsule but can also be secondary to fibrous tissue, compressed liver or prominent sinusoids. ${ }^{67,68}$

Lesion growth is also associated with risk of malignancy. HCCs have demonstrated variable tumor volume doubling times, from 9 days to years depending on tumor differentiation status. ${ }^{69,70}$ Hepatocarcinogenesis progresses with lesion growth and therefore a larger lesion size is also associated with HCC. ${ }^{71}$ Many guidelines use 1 and $2 \mathrm{~cm}$ as cut-offs for lesion size and associated risk of HCC. ${ }^{72}$ Growth parameters as recommended by the Organ Procurement and Transplant Network/United Network for Organ Sharing define $\geq 50 \%$ growth in a $<6$ month period as associated with increased risk of HCC. LIRADS has added further parameters of $\geq 100 \%$ growth in a $>6$ month period or a new lesion $>1 \mathrm{~cm} .{ }^{48}$

LIRADS also defines ancillary features, which although not strongly sensitive or specific may aid with lesions where diagnosis is indeterminate based on the major features above. The presence of hyperintensity or diffusion restriction improves sensitivity, particularly for smaller lesions but is not specific for HCC. ${ }^{73}$ HCCs are typically of mild to moderate T2 hyperintensity. High T2 intensity is associated with benign lesions, such as hemangiomas or cysts. Indeed, as dedifferentiation progresses, HCCs have demonstrated iso- to hypointensity on T2-weighted sequences. Mosaic pattern is associated with the variability of tissue components associated with HCC (Supplementary Fig. 2). Its utility is most useful in larger lesions, where regions of enhancement, necrosis, hemorrhage and fibrosis may be present in a tumor. ${ }^{13}$ Finally, a nodule-in-nodule appearance is typically associated with dedifferentiation of (enhancing) HCC in a larger (isoenhancing) cirrhotic nodule.

Hepatobiliary contrast agents are contrast agents taken up by normally functioning hepatocytes via the OATP1 transporter. These agents behave like standard extracellular contrast, with distribution in vessel and extracellular spaces in the early phases. However, due to their uptake in hepatocytes, there is enhancement of normal hepatic parenchyma in the hepatocellular phase (15-20minutes) with little to no uptake in non-hepatocellular or non-functioning hepatocytecontaining lesions, such as HCC. The use of hepatocytespecific contrast agents in assessing for HCC demonstrated sensitivity levels of $86 \%$ in a large meta-analysis. ${ }^{74} \mathrm{~A}$ potential disadvantage is the reported breath hold artifacts during dynamic arterial phase witnessed in patients while using this contrast agent. ${ }^{75}$

\section{CEUS}

CEUS utilizes the generation of harmonic signals from resonating microbubbles to form a signal. These microbubbles consist of a lipid shell, measuring 3-5 $\mu \mathrm{m}$ in diameter, containing a perfluorocarbon gas. This is much larger than the molecules used in CT or MRI contrast agents and as a result remain completely intravascular, leading to differences in enhancement patterns between CEUS and conventional CT/MR imaging.

CEUS is utilized by many societies in their guidance on diagnosis of HCC, as it has been demonstrated as a valuable contributor in evaluating nodules in a cirrhotic liver. ${ }^{76}$ Specific indications have been proposed and may include assessment of a nodule $\geq 1 \mathrm{~cm}$ in ultrasound, indeterminate nodules on $\mathrm{CT} / \mathrm{MR}$ imaging, indeterminate nodules post-biopsy, and nodules in individuals where timing of the arterial phase may be difficult to ascertain, as well as visualization of lesions not seen on non-contrast ultrasound, selection of the most appropriate lesion for biopsy, assessment of tumor thrombus, and for post-treatment surveillance. ${ }^{77}$

The diagnosis of HCC with CEUS can be based on numerous imaging features (Supplementary Fig. 3). Arterial phase hyperenhancement is identified when enhancement is greater than the background liver within approximately the first $45 \mathrm{~s}$. This may be present in the entire nodule or part of a nodule, when filling of the nodule occurs in a centripetal fashion. Progressive washout of the nodule is also typical of HCC. The onset of washout begins usually after $60 \mathrm{~s}$ but the nodule itself typically retains some internal enhancement, although less than surrounding hepatic parenchyma. ${ }^{77}$ As with cross-sectional imaging, other features, such as increase in size over time, nodule-within-a-nodule appearance and mosaic appearance on grayscale imaging, are all factors making the diagnosis of HCC more likely. The validity of CEUS in lesion characterization and diagnostic performance has been proven in various studies. ${ }^{74,78} \mathrm{~A}$ recent metaanalysis demonstrated similar diagnostic performance of CEUS versus gadolinium-enhanced MRI in detecting HCC, with a sensitivity/positive predictive value of $84.4 \% / 89.3 \%$ for CEUS and $77.5 \% / 83.6 \%$ for gadolinium-enhanced MRI. ${ }^{74}$

CEUS has its limitations. The most important limitation is that evaluation of the entire liver is not possible, potentially missing other nodules. Characterization of only one nodule is possible with one injection, however. The enhancement patterns overlap with several other benign lesions. Patient factors may limit visibility, with the technique being highly operator-dependent. Highly cirrhotic or fatty livers are challenging. Pseudoenhancement can also occur secondary to echogenic objects deep in the liver. ${ }^{79}$

\section{Novel techniques}

Techniques to improve the imaging of HCC are continuously evolving. In CT, perfusion analysis, dual-energy and textural analyses are being investigated to improve the sensitivity of this modality. With MRI, MR spectroscopy, MR elastography and T1 mapping are potential novel techniques.

\section{CT perfusion}

CT perfusion has the ability to assess hemodynamic changes in the liver or part of the liver. It is based on the increase and subsequent decrease in the concentration of iodinated contrast material in a region of liver as a function of time. It depends on factors such as blood volume, blood flow to an area, and permeability of capillaries to the contrast agent. ${ }^{80}$ Parameters which may be assessed include blood flow in the artery, mean transit time between arterial inflow and venous outflow, and blood volume. The relationship of perfusion to pathological angiogenesis is not well understood. ${ }^{81}$ It is believed to be associated with microvessel density within a tumor, which affects blood volume and flow. Mean transit time can be decreased due to increased vascular permeability in tumor vessels and the presence of arteriovenous shunts.

This is also true in the assessment of HCC with blood volume, blood flow, hepatic perfusion index and arterial perfusion all being lower in normal hepatic parenchyma than in HCC. ${ }^{82}$ Perfusion may aid in diagnosis and may also aid in grading tumors, with estimation of blood volume, mean blood flow and permeability surface area findings all being 
significantly higher in well-differentiated HCC versus other grades. ${ }^{83,84} \mathrm{CT}$ perfusion may also assess tumor response and predict survival following particle embolization or treatment with sorafenib. ${ }^{85,86}$ Factors such as blood flow and blood volume were found to significantly decrease after 1 day of treatment in an in vitro study. ${ }^{87}$ Finally, CT perfusion may also aid in detecting recurrence, with the utility of the perfusion index and volumetric arterial enhancement fraction color mapping allowing earlier detection of recurrence following microwave ablation and transarterial chemoembolization (TACE). 88,89

There are several challenges to the routine clinical use of $\mathrm{CT}$ perfusion in the assessment of $\mathrm{HCC}$. For one, radiation dose reduction is required, as CT perfusion can result in higher radiation with doses ranging from 7.3 to $30.6 \mathrm{mSv}^{90}$ In addition, lack of standardized protocol, reproducibility, motion artifacts and inability to sample the whole tumor are all further issues. ${ }^{81,83}$

\section{Dual-energy CT}

Dual-energy CT was first used clinically in 2006. It allows acquisition of information from two different $x$-ray spectra almost instantaneously, depending on the equipment used. Materials with different atomic numbers behave differently in these spectra, and this allows for improved analysis of this contrast in composition. ${ }^{91}$

This can be applied to the analysis of HCC in numerous ways. The improved contrast can allow greater differentiation of fat in liver lesions that can be associated with HCC. ${ }^{92}$ The enhancement of small HCCs can also be amplified due to increased iodine concentration, without any increase in image noise (Fig. 4). ${ }^{93}$ Various alterations in imaging techniques, such as utilizing monochromatic energy levels of 40$70 \mathrm{keV}$, may also demonstrate improved detection rates (Fig, 4). ${ }^{94}$ Dual-energy CT may also have applications in assessing perfusional characterization of a lesion, which has been argued at potentially offering similar assessment capabilities as perfusion $\mathrm{CT}$. $^{95}$

\section{Textural analysis}

Textural analysis is an objective measure of tumor heterogeneity on CT and MRI. This is achieved by analyzing the distribution of pixels within the lesion (Fig. 5)..$^{96}$ The most commonly used method is a statistical-based model. Tumors demonstrate heterogeneity on numerous levels; this is secondary to angiogenesis, variations in cellularity, areas of necrosis, and extravascular extracellular matrix. ${ }^{97}$ Tumors with increased intratumoral heterogeneity are associated with poorer prognosis. ${ }^{98}$

With regards HCC, textural analysis has demonstrated potential in predicting survival and may be beneficial in identifying individuals suitable for TACE. ${ }^{99}$ In the largest of these studies, CT textural analysis demonstrated an ability to differentiate patients who benefitted most in terms of survival when treated with TACE and sorafenib compared to TACE alone. ${ }^{99}$ MR texture analysis is a more recent development assessing heterogeneity of pixels on $\mathrm{T} 1$ sequences post-contrast and this has demonstrated some potential in assessing tumor grade. ${ }^{100}$

A possible limitation of this technology is the lack of an agreed technique between studies, making comparison and ultimately validation difficult. The time needed to analyze these studies and create adequate 3D models is also not well understood, and whether this technique could be realistically introduced into the routine clinical schedule remains to be demonstrated due to the volume of data involved.

\section{MR spectroscopy (MRS)}

MRS assesses the concentrations of various metabolites within tissue. By doing this, it can assess the composition of a particular area of tissue but also indirectly assess the pathophysiology and metabolism. ${ }^{101}$ The hydrogen $\left({ }^{1} \mathrm{H}\right)$ nucleus is most commonly utilized for MRS followed by phosphorus-31 $\left({ }^{31} \mathrm{P}\right)$, with carbon-13 $\left({ }^{13} \mathrm{C}\right)$ as another potential option.

In $\mathrm{HCC}$, the presence of malignancy can be identified by assessing choline peaks and proton resonances of mobile lipids. ${ }^{102}$ MRS has demonstrated efficacy in assessing response following TACE by determining levels of choline and its derivatives. Mean choline/lipid ratios are decreased following successful TACE treatment. ${ }^{103}$ Tumor progression has been associated with an increase in phosphomonoesters. ${ }^{104}$

The major limitation of MRS is its low sensitivity in assessing smaller lesions, due excessive signal-to-noise ratio and effects of motion. ${ }^{105}$ MRS can be technically demanding, with significant impact on scan time, and it needs a trained and expert physicist for input, and needs additional processing. All these features make MRS a research tool mainly and not easily applicable in routine clinical practice.

\section{Elastography}

The incidence of HCC increases with the progression of hepatic fibrosis and stiffness associated with chronic inflammation of the liver. ${ }^{106}$ Assessment of hepatic stiffness was first utilized with ultrasonography, creating ultrasound elastography at the turn of the century. Ultrasound elastography has demonstrated high accuracy for staging liver fibrosis and ultimately allowing assessment of risk for HCC. ${ }^{107,108}$ The development of point and 2D-shear wave may also allow increased characterization and differentiation of focal liver masses based on their stiffness. ${ }^{109}$

MR elastography (MRE) assesses the mechanical properties of tissues by analyzing the response of mechanical shear waves at a low frequency after they pass through the liver. ${ }^{110}$ The utility of this technique, like ultrasound elastography, is predominantly to assess for hepatic fibrosis. However, recent evidence has demonstrated a link between tumor grade and tumor stiffness, with malignant tumors demonstrating greater stiffness on MRE (Fig. 6). ${ }^{111}$ A threshold of $5.0 \mathrm{kPa}$ is postulated as a threshold to allow differentiation between benign and malignant tumors. ${ }^{111}$

Stiffness may also indicate grade of malignancy, with a recent study indicating increased stiffness with increased tumor grade. ${ }^{112}$ Data regarding utility of MRE in the diagnosis of HCC is lacking, but it still may be useful for characterizing a lesion by demonstrating increased liver stiffness that is suggestive of otherwise unsuspected liver fibrosis in the background parenchyma. A recent study has shown that stiffness of HCC measured with MRE may be useful to differentiate poorly differentiated HCC from moderately to welldifferentiated HCC; ${ }^{112}$ however, this needs to be confirmed in larger studies.

\section{Intravoxel incoherent motion imaging (IVIM)}

The diffusion motion of water in a region of tissue is assessed using diffusion-weighted imaging. Diffusion may be secondary 
Navin P.J. et al: Hepatocellular carcinoma- advances in imaging
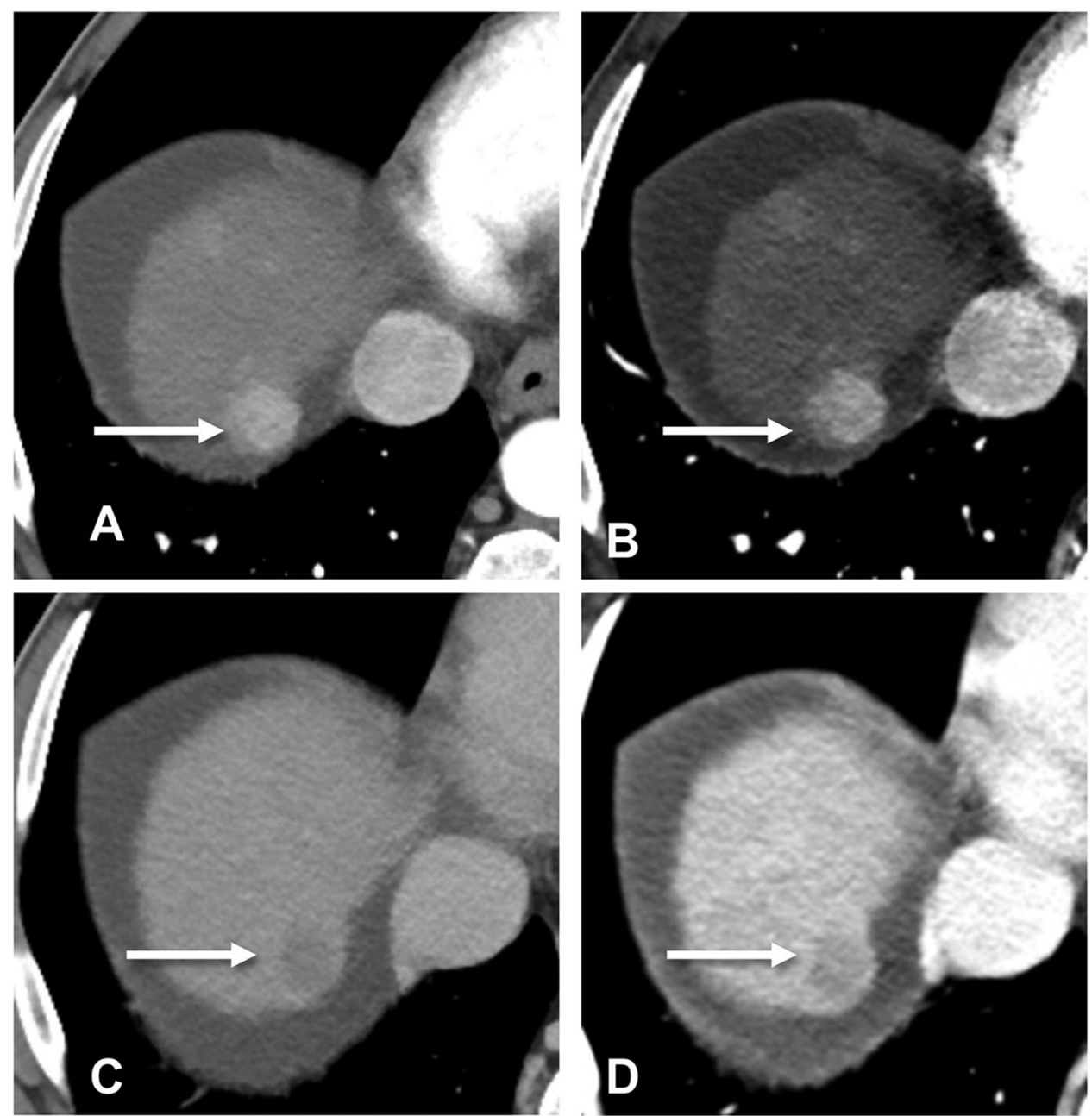

Fig. 4. Dual-energy computed tomography demonstrating a hepatocellular carcinoma with arterial phase hyperenhancement on 0.6 linear blend (A) and $50 \mathrm{keV}$ (B) imaging. The hepatocellular carcinoma also demonstrates washout on delayed linear blend (C) and 50 keV (D) images. (Images courtesy of Dr. Joel G. Fletcher, Radiology, Mayo Clinic, Rochester, MN, USA.)

to molecular diffusion or secondary to microcirculation in vessels. ${ }^{113}$ The sensitivity of this imaging technique is based on the $b$-value. Low b-values offer a high signal-to-noise ratio but decreased sensitivity in discerning molecular diffusion to diffusion secondary to microcirculation. High b-values allow almost complete elimination of diffusion secondary to
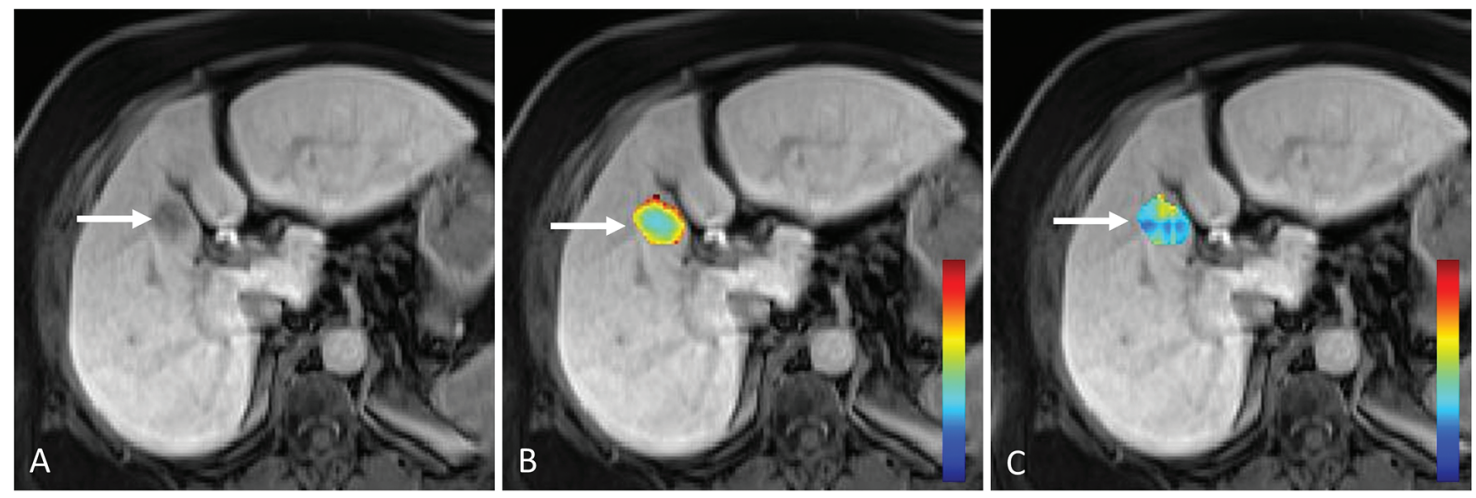

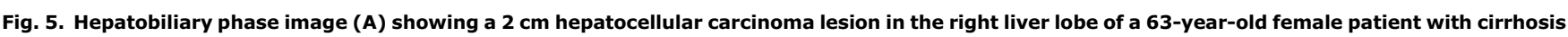
and hepatitis C. Texture maps of Haralick featuring Energy ( $B$, average value 0.005 ; range $0-0.03)$ and Contrast $(C$, range $0-70$; average value 20.6) are overlaid on the lesion. (Images courtesy of Dr. Bachir Taouli and Dr. Stefanie Hectors, Mount Sinai Medical Center, New York, NY, USA.) 

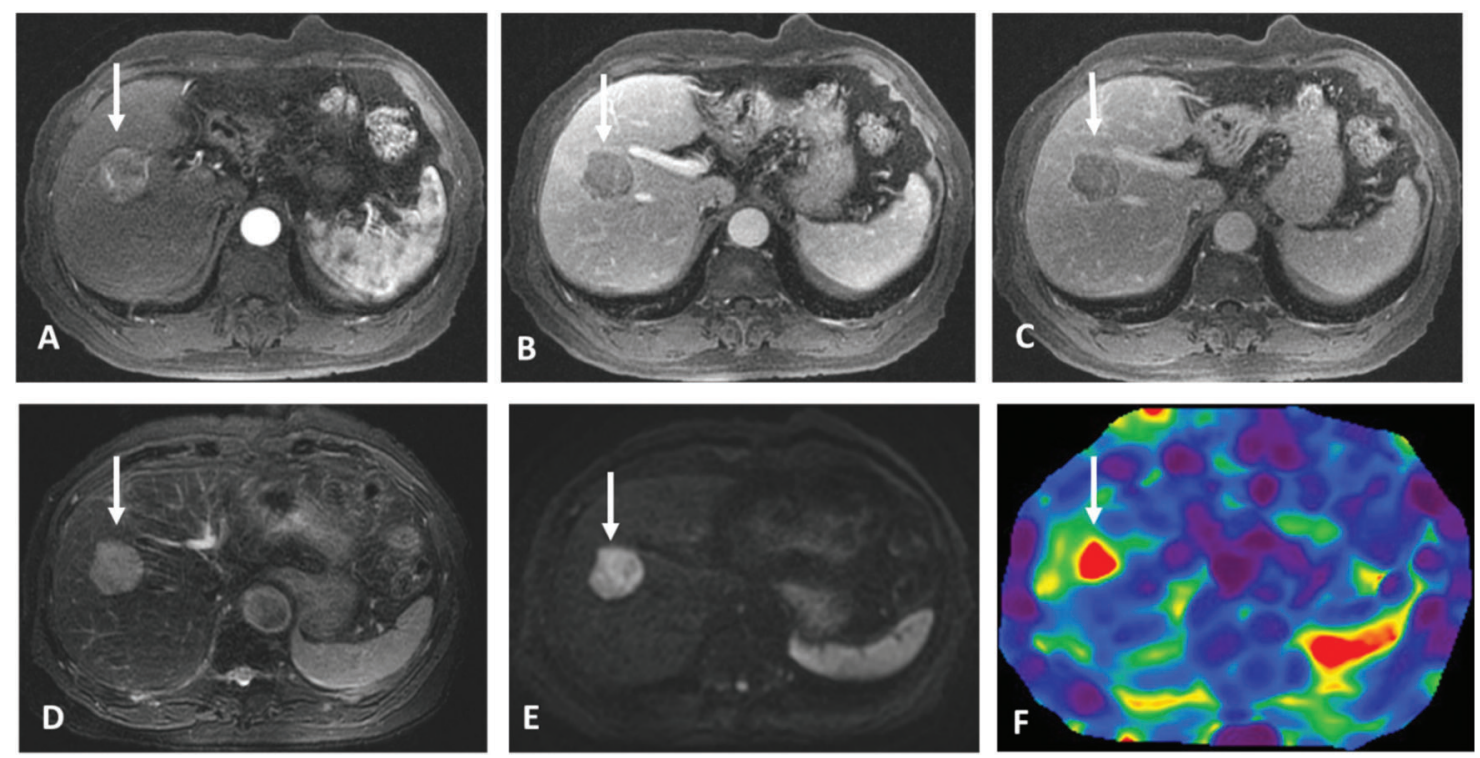

Fig. 6. Axial magnetic resonance imaging of the abdomen of a 63-year-old patient with chronic hepatitis. (A) Demonstrates mosaic arterial phase hyperenhancement with washout and pseudocapsule formation on portal venous phase (B) and delayed phase imaging (C). The mass demonstrates moderate signal intensity on T2-weighted image (D), moderate restricted diffusion (E) and increased stiffness on magnetic resonance elastography (F). The mean stiffness of the hepatocellular carcinoma was $8.2 \mathrm{kPa}$ and the background hepatic stiffness of only $2.9 \mathrm{kPa}$ suggestive of a non-cirrhotic liver parenchyma.

microcirculation but provide poor image quality due to low signal. ${ }^{114,115}$ IVIM imaging utilizes a range of $b$-values to offer information on both molecular diffusion and the microcirculation within the lesion. Parameters which are frequently utilized are the true molecular-diffusion coefficient (D), perfusion related diffusion coefficient ( $\left.D^{*}\right)$ and the perfusion fraction (f) (Fig. 7).

There is limited data available on the use of IVIM in HCC. Apparent diffusion coefficient values are lower in malignant lesions compared to benign lesions. ${ }^{116} D$ and $D^{*}$ values, however, were found to be more reliable with increased accuracy in diagnosing and grading malignant liver lesions compared to apparent diffusion coefficient values. ${ }^{117}$ In a small study, IVIM was successful in differentiating HCC from focal nodular hyperplasia. ${ }^{118}$ Additionally, the utility of IVIM in assessing response to therapy has also been assessed in vitro, yielding positive results. ${ }^{119}$

\section{T1 mapping}

T1 mapping is a method utilized to assess T1 relaxation time within tissue. It has been employed in cardiac MRI with or without IV contrast to asses for fibrotic changes within the myocardium, presence of myocardial infarction, presence of a cardiomyopathy or myocarditis, and presence of amyloid or excessive iron deposition. ${ }^{120}$

Functioning hepatocytes take up hepatocyte-specific contrast agents. This allows assessment of hepatic vascularity, as with extracellular contrast media, but also allows assessment of specific hepatocellular properties. Measuring T1 relaxation time within tumors before and also after the administration of gadoxetic acid therefore allows quantitative evaluation of properties and uptake within these tumors. ${ }^{121}$ With this combined use of T1 mapping and Gd-EOB-DTPA, it may be possible to differentiate normal liver, fatty liver only and non-alcoholic steatohepatitis, ${ }^{122}$ and assess for the presence of fibrosis ${ }^{123}$ or focal lesions, such as hemangiomas from hepatic metastases. ${ }^{124}$ There is also evidence that it may allow adequate grading of HCC (Fig. 8). ${ }^{125}$

\section{Radiogenomics}

Human disease is now assessed on a genomic level. With the completion of the Human Genome Project, molecular biomarkers have been utilized to guide individualized treatment of the patient's particular pathology. Early research into this area has demonstrated potential, but these are often based on isolated case reports. ${ }^{126}$ As radiology plays an integral part in disease diagnosis and management, attempts have been made to correlate imaging features to the genetic data associated with a condition. Radiogenomics is a term coined to describe the process of correlating the imaging phenotype to the disease genotype and associated characteristics.

The field of Radiogenomics is only beginning to flourish. In the assessment of HCC, the expression of $74 \%$ of the 6,732 genes associated with HCC could be predicted based on 28 imaging features. ${ }^{127}$ This was achieved by assessing for the presence of 138 separate imaging traits in $28 \mathrm{HCCs}$. For instance, a channel of radio-dense signal during arterial phase CT was taken to represent internal arteries. By creating and "association map" between this imaging feature and gene expression, certain relationships were uncovered. Using this method, 91 genes were shown to be associated with the presence of microscopic venous invasion. The presence of these genes could be predicted based on the presence of internal arteries and absence of hypodense halos. ${ }^{127}$ In a separate study, doxorubicin resistance could be predicted based on the presence of 61 genes. Following analysis of imaging features, the presence of a poorly defined tumor margin was associated with this genetic signature and, ergo, doxorubicin resistance. $^{128}$ 


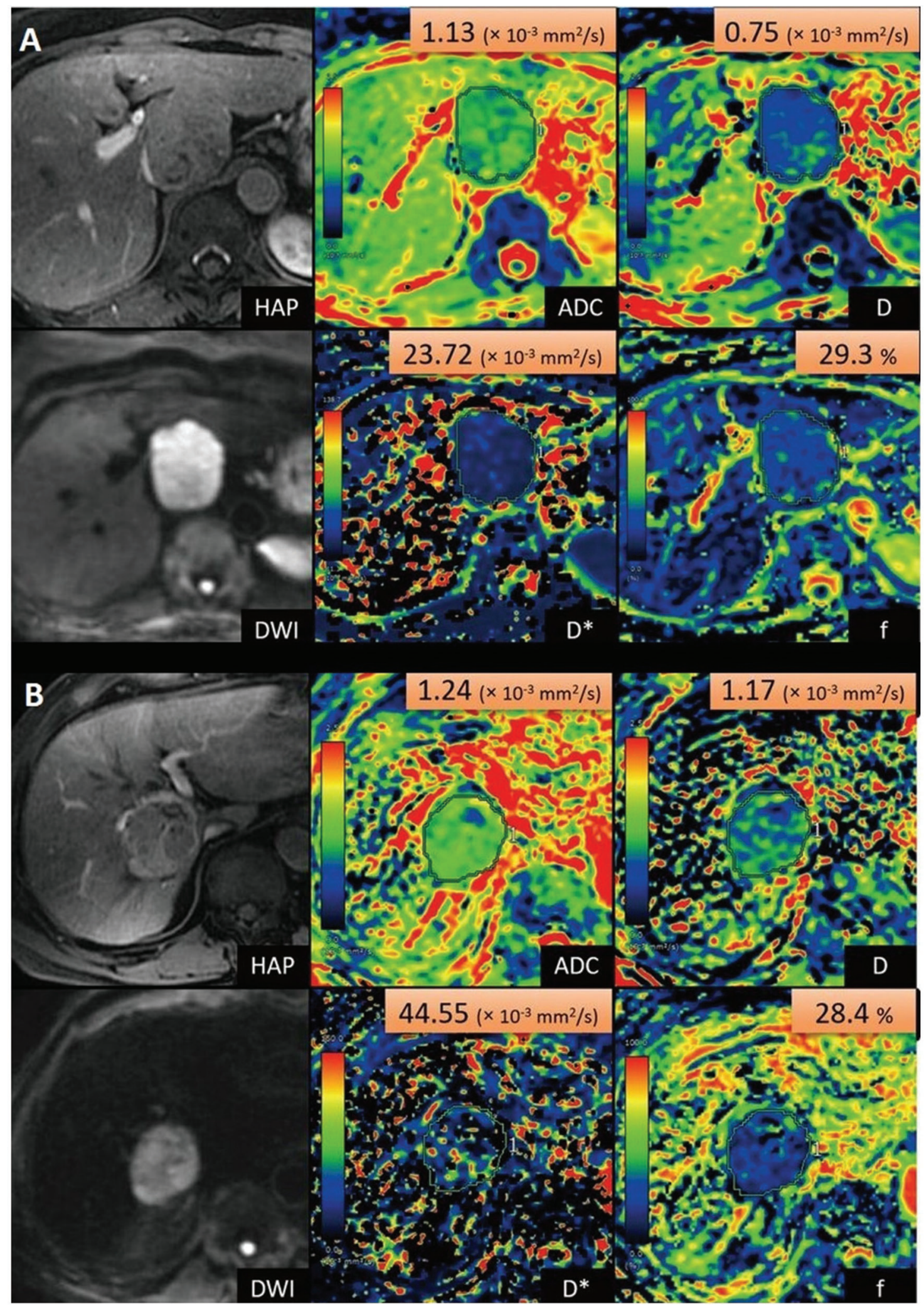

Fig. 7. Intravoxel incoherent motion imaging of hepatocellular carcinoma. Hepatic arterial phase (HAP), diffusion weighted imaging (DWI), apparent diffusion coefficient map (ADC), true molecular-diffusion coefficient map (D), perfusion related diffusion coefficient map ( $D^{*}$ ) and the perfusion fraction map (f) in a high grade $(A$, top panel) and a low-grade hepatocellular carcinoma (B, bottom panel). Both hepatocellular carcinomas show hyperenhancement and restricted diffusion with lower ADC in high grade hepatocellular carcinoma. Cut-off values of $1.14 \times 10^{-3} \mathrm{~mm}^{2} / \mathrm{sec}$ for ADC and $1.07 \times 10^{-3} \mathrm{~mm}^{2} / \mathrm{sec}$ for $\mathrm{D}$ have been postulated to differentiate high (A) from low grade lesions (B). (Images courtesy of Dr. Utaroh Motosugi and Dr. Shintaro Ichikawa, Yamanashi University, Japan.) 
Navin P.J. et al: Hepatocellular carcinoma- advances in imaging

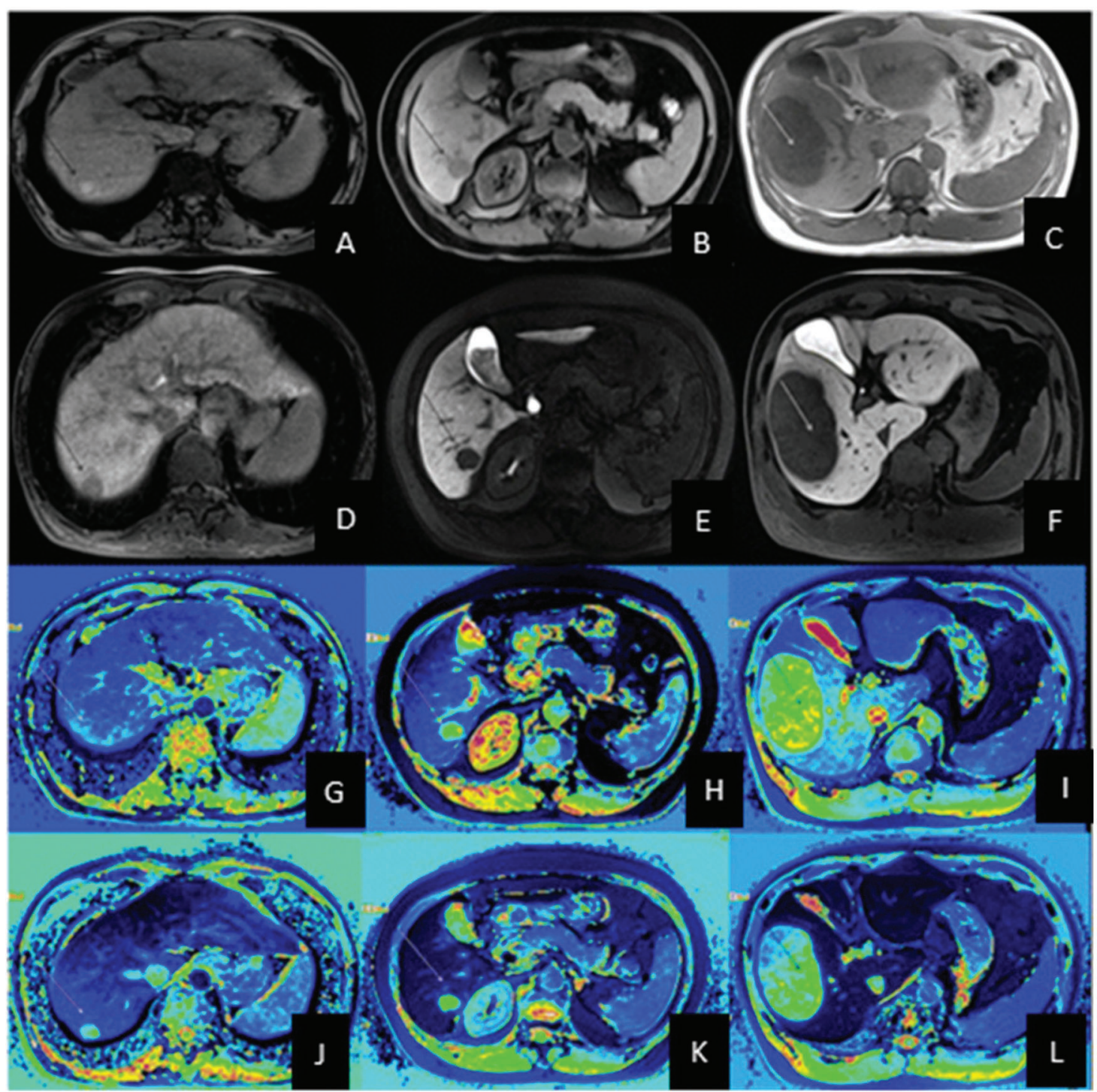

Fig. 8. Magnetic resonance imaging of the abdomen of separate patients with low grade (column 1 ), intermediate grade (column 2 ) and high grade (column 3 ) hepatocellular carcinoma. Top row (A to C) showing T1-weighted images, second row (D to F) showing hepatobiliary phase images, third row (G to I) showing T1 mapping of T1weighted images, and bottom row ( $\mathrm{J}$ to L) illustrating the T1 mapping of hepatobiliary phase images. Column $1: \mathrm{T} 1 \mathrm{p} 892 \mathrm{~ms}, \mathrm{~T} 1 \mathrm{e} 388 \mathrm{~ms}, \mathrm{~T} 1 \mathrm{~d}=504 \mathrm{~ms}$, T1d $\%=56.50 \%$; Column 2: T1p 1696 ms, T1e 1444 ms, T1d = 252 ms, T1d \% = 14.90 \%; Column 3: T1p $2134 \mathrm{ms,} \mathrm{T1e} 1494 \mathrm{ms,} \mathrm{T1d} \mathrm{=} \mathrm{640} \mathrm{ms,} \mathrm{T1d} \mathrm{\%} \mathrm{=} \mathrm{30.00} \mathrm{\% .} \mathrm{In} \mathrm{general,} \mathrm{T1d} \mathrm{and} \mathrm{T1d \%}$ decrease with increasing tumor grade. T1p (pre-contrast), T1e (enhanced), T1d (difference) between T1p and T1e and T1d\% percentage difference between T1p and T1e. (Images modified and reproduced with permission from Peng et al., 2016 (reference.126).)

\section{Positron emission tomography (PET)}

PET CT with fluorodeoxyglucose (FDG) has limited use in HCC despite its popularity in the assessment of other malignancies. Although increased uptake of FDG has been shown to correlate with increased tumor grade, there is no current role within any diagnostic algorithm due to the low sensitivity of FDG PET in assessing tumors. However, FDG PET is useful for detection of metastatic HCCs elsewhere (Supplementary Fig. 4). The metastatic lesions take up FDG well, suggesting a more aggressive phenotype of HCC.

Flurodeoxygalactose is considered as a possible alternative to FDG. As the name suggests, it utilizes galactose metabolism instead of glucose metabolism as a tracer for intrahepatic and extrahepatic HCC. In a retrospective study, sensitivity of flurodeoxygalactose PET/CT was comparable to multiphase CT, with high specificity. ${ }^{129}$

\section{Conclusions}

HCC is a malignancy associated with a high mortality. Early identification with a robust screening program is essential and must adapt into a wider management algorithm. Professional study groups have advocated guidelines to aid clinicians and radiologists in the management of HCC. LIRADS attempts to standardize the lexicon associated with HCC and to create an imaging algorithm to improve the homogeneity of data acquisition and image reporting.

In contrast, radiogenomics and other advances in imaging are designed to appreciate the heterogeneity of HCC with 
imaging and promote treatment individualized towards each tumor-specific signature. Advances such as T1 mapping, textural analysis and perfusion imaging have the potential to allow greater accuracy in diagnosis and staging, combined with potential direction on personalized treatment.

\section{Conflict of interest}

The authors have no conflict of interests related to this publication.

\section{Author contributions}

Contributed to literature review and manuscript preparation (PN), manuscript revision and preparation (SKV).

\section{References}

[1] Altekruse SF, McGlynn KA, Reichman ME. Hepatocellular carcinoma incidence, mortality, and survival trends in the United States from 1975 to 2005. J Clin Oncol 2009;27:1485-1491. doi: 10.1200/JCO.2008.20.7753.

[2] Petrick JL, Kelly SP, Altekruse SF, McGlynn KA, Rosenberg PS. Future of hepatocellular carcinoma incidence in the United States forecast through 2030. J Clin Oncol 2016;34:1787-1794. doi: 10.1200/JCO.2015.64.7412.

[3] Forner A, Llovet JM, Bruix J. Hepatocellular carcinoma. Lancet 2012;379: 1245-1255. doi: 10.1016/S0140-6736(11)61347-0.

[4] Akinyemiju T, Abera S, Ahmed M, Alam N, Alemayohu MA, Allen $C$, et al. The burden of primary liver cancer and underlying etiologies from 1990 to 2015 at the global, regional, and national level: Results from the global burden of disease study 2015. JAMA Oncol 2017;3:1683-1691. doi: 10. 1001/jamaoncol.2017.3055.

[5] Siegel R, Naishadham D, Jemal A. Cancer statistics, 2013. CA Cancer J Clin 2013;63:11-30. doi: 10.3322/caac.21166.

[6] Takayama T, Makuuchi M, Kojiro M, Lauwers GY, Adams RB, Wilson SR, et al. Early hepatocellular carcinoma: pathology, imaging, and therapy. Ann Surg Oncol 2008;15:972-978. doi: 10.1245/s10434-007-9685-0.

[7] Nishida N, Goel A. Genetic and epigenetic signatures in human hepatocellular carcinoma: a systematic review. Curr Genomics 2011;12:130-137. doi: $10.2174 / 138920211795564359$.

[8] Trevisani F, Cantarini MC, Wands JR, Bernardi M. Recent advances in the natural history of hepatocellular carcinoma. Carcinogenesis 2008;29: 1299-1305. doi: 10.1093/carcin/bgn113.

[9] International Working Party. Terminology of nodular hepatocellular lesions. Hepatology 1995;22:983-993. doi: 10.1002/hep.1840220341.

[10] Kitao A, Matsui O, Yoneda N, Kozaka K, Shinmura R, Koda W, et al. The uptake transporter OATP8 expression decreases during multistep hepatocarcinogenesis: correlation with gadoxetic acid enhanced MR imaging. Eur Radiol 2011;21:2056-2066. doi: 10.1007/s00330-011-2165-8.

[11] Pathologic diagnosis of early hepatocellular carcinoma: a report of the international consensus group for hepatocellular neoplasia. Hepatology 2009; 49:658-664. doi: 10.1002/hep.22709.

[12] Khalili K, Kim TK, Jang HJ, Yazdi LK, Guindi M, Sherman M. Indeterminate 1-2-cm nodules found on hepatocellular carcinoma surveillance: biopsy for all, some, or none? Hepatology 2011;54:2048-2054. doi: 10.1002/hep. 24638.

[13] Stevens WR, Gulino SP, Batts KP, Stephens DH, Johnson CD. Mosaic pattern of hepatocellular carcinoma: histologic basis for a characteristic CT appearance. J Comput Assist Tomogr 1996;20:337-342. doi: 10.1097/00004728199605000-00001.

[14] Edmondson HA, Steiner PE. Primary carcinoma of the liver: a study of 100 cases among 48,900 necropsies. Cancer 1954;7:462-503. doi: 10 . 1002/1097-0142(195405)7:3<462::AID-CNCR2820070308>3.0.CO;2-E.

[15] Kojiro M. Histopathology of liver cancers. Best Pract Res Clin Gastroenterol 2005;19:39-62. doi: 10.1016/j.bpg.2004.10.007.

[16] Katyal S, Oliver JH 3rd, Peterson MS, Ferris JV, Carr BS, Baron RL. Extrahepatic metastases of hepatocellular carcinoma. Radiology 2000;216:698703. doi: $10.1148 /$ radiology.216.3.ro0se24698.

[17] El-Serag HB, Rudolph KL. Hepatocellular carcinoma: epidemiology and molecular carcinogenesis. Gastroenterology 2007;132:2557-2576. doi: 10.1053/j.gastro.2007.04.061.

[18] Tsukuma H, Hiyama T, Tanaka S, Nakao M, Yabuuchi T, Kitamura T, et al. Risk factors for hepatocellular carcinoma among patients with chronic liver disease. N Engl J Med 1993;328:1797-1801. doi: 10.1056/NEJM199306243282501.
[19] Colombo M, de Franchis R, Del Ninno E, Sangiovanni A, De Fazio C, Tommasini $\mathrm{M}$, et al. Hepatocellular carcinoma in Italian patients with cirrhosis. N Engl J Med 1991;325:675-680. doi: 10.1056/NEJM199109053251002.

[20] Zaman SN, Johnson PJ, Williams R. Silent cirrhosis in patients with hepatocellular carcinoma. Implications for screening in high-incidence and lowincidence areas. Cancer 1990;65:1607-1610. doi: 10.1002/1097-0142 (19900401)65:7<1607::AID-CNCR2820650726>3.0.CO;2-2.

[21] Liver Cancer Study Group of Japan. Primary liver cancer in Japan. Clinicopathologic features and results of surgical treatment. Ann. Surg 1990;211: 277-287.

[22] World health organization. Hepatitis B. Factsheet, 2016.

[23] Davila JA, Morgan RO, Shaib Y, McGlynn KA, El-Serag HB. Hepatitis C infection and the increasing incidence of hepatocellular carcinoma: a populationbased study. Gastroenterology 2004;127:1372-1380. doi: $10.1053 / \mathrm{j}$. gastro.2004.07.020.

[24] Turati F, Galeone C, Rota M, Pelucchi C, Negri E, Bagnardi V, et al. Alcohol and liver cancer: a systematic review and meta-analysis of prospective studies. Ann Oncol 2014;25:1526-1535. doi: 10.1093/annonc/mdu020.

[25] Elmberg M, Hultcrantz R, Ekbom A, Brandt L, Olsson S, Olsson R, et al. Cancer risk in patients with hereditary hemochromatosis and in their firstdegree relatives. Gastroenterology 2003;125:1733-1741. doi: 10.1053/j. gastro.2003.09.035

[26] Chen J, Han Y, Xu C, Xiao T, Wang B. Effect of type 2 diabetes mellitus on the risk for hepatocellular carcinoma in chronic liver diseases: a meta-analysis of cohort studies. Eur J Cancer Prev 2015;24:89-99. doi: 10.1097/CEJ. 0000000000000038 .

[27] Larsson SC, Wolk A. Overweight, obesity and risk of liver cancer: a metaanalysis of cohort studies. $\mathrm{Br}$ J Cancer 2007;97:1005-1008. doi: 10 . 1038/sj.bjc. 6603932.

[28] Singal AG, El-Serag HB. Hepatocellular carcinoma from epidemiology to prevention: Translating knowledge into practice. Clin Gastroenterol Hepatol 2015;13:2140-2151. doi: 10.1016/j.cgh.2015.08.014.

[29] Liu Y, He Y, Li T, Xie L, Wang J, Qin X, et al. Risk of primary liver cancer associated with gallstones and cholecystectomy: a meta-analysis. PLoS One 2014;9:e109733. doi: 10.1371/journal.pone.0109733.

[30] Nelson DR, Teckman J, Di Bisceglie AM, Brenner DA. Diagnosis and management of patients with $\alpha 1$-antitrypsin (A1AT) deficiency. Clin Gastroenterol Hepatol 2012;10:575-580. doi: 10.1016/j.cgh.2011.12.028.

[31] Stewart MF. Review of hepatocellular cancer, hypertension and renal impairment as late complications of acute porphyria and recommendations for patient follow-up. J Clin Pathol 2012;65:976-980. doi: 10.1136/jclinpath2012-200791.

[32] Kim WR, Lake JR, Smith JM, Skeans MA, Schladt DP, Edwards EB, et al. OPTN/SRTR 2015 Annual Data Report: Liver. Am J Transplant 2017;17 Suppl 1:174-251. doi: 10.1111/ajt.14126.

[33] Byam J, Renz J, Millis JM. Liver transplantation for hepatocellular carcinoma. Hepatobiliary Surg Nutr 2013;2:22-30. doi: 10.3978/j.issn.2304-3881. 2012.11.03.

[34] Torres DM, Williams CD, Harrison SA. Features, diagnosis, and treatment of nonalcoholic fatty liver disease. Clin Gastroenterol Hepatol 2012;10:837858. doi: $10.1016 / j . c g h .2012 .03 .011$.

[35] Guzman G, Brunt EM, Petrovic LM, Chejfec G, Layden TJ, Cotler SJ. Does nonalcoholic fatty liver disease predispose patients to hepatocellular carcinoma in the absence of cirrhosis? Arch Pathol Lab Med 2008;132:17611766. doi: 10.1043/1543-2165-132.11.1761.

[36] Malik SM, Gupte PA, de Vera ME, Ahmad J. Liver transplantation in patients with nonalcoholic steatohepatitis-related hepatocellular carcinoma. Clin Gastroenterol Hepatol 2009;7:800-806. doi: 10.1016/j.cgh.2009.02.025.

[37] Margini C, Dufour JF. The story of HCC in NAFLD: from epidemiology, across pathogenesis, to prevention and treatment. Liver Int 2016;36:317-324. doi: $10.1111 /$ liv.13031.

[38] Heimbach JK, Kulik LM, Finn RS, Sirlin CB, Abecassis MM, Roberts LR, et al. AASLD guidelines for the treatment of hepatocellular carcinoma. Hepatology 2018;67:358-380. doi: 10.1002/hep.29086.

[39] EASL-EORTC clinical practice guidelines: management of hepatocellular carcinoma. J Hepatol 2012;56:908-943. doi: 10.1016/j.jhep.2011.12.001.

[40] Verslype C, Rosmorduc O, Rougier P. Hepatocellular carcinoma: ESMOESDO Clinical Practice Guidelines for diagnosis, treatment and follow-up. Ann Oncol 2012;23 Suppl 7:vii41-vii48. doi: 10.1093/annonc/mds225.

[41] 2014 KLCSG-NCC Korea Practice Guideline for the Management of Hepatocellular Carcinoma. Gut Liver 2015;9:267-317. doi: 10.5009/gnl14460.

[42] Kokudo N, Hasegawa $\mathrm{K}$, Akahane $\mathrm{M}$, Igaki $\mathrm{H}$, Izumi $\mathrm{N}$, Ichida $\mathrm{T}$, et al. Evidence-based clinical practice guidelines for hepatocellular carcinoma: The Japan Society of Hepatology 2013 update (3rd JSH-HCC Guidelines). Hepatol Res 2015;45. doi: 10.1111/hepr.12464.

[43] Benson AB 3rd, D'Angelica MI, Abbott DE, Abrams TA, Alberts SR, Saenz DA et al. NCCN Guidelines Insights: Hepatobiliary Cancers, Version 1.2017. J Natl Compr Canc Netw 2017;15:563-573. doi: 10.6004/jnccn.2017. 0059. 
[44] Marrero JA, Ahn J, Rajender Reddy K. ACG clinical guideline: the diagnosis and management of focal liver lesions. Am J Gastroenterol 2014;109: 1328-1347. doi: 10.1038/ajg.2014.213.

[45] Singal AG, Pillai A, Tiro J. Early detection, curative treatment, and survival rates for hepatocellular carcinoma surveillance in patients with cirrhosis: a meta-analysis. PLoS Med 2014;11:e1001624. doi: 10.1371/journal.pmed. 1001624.

[46] Zhang $\mathrm{BH}$, Yang $\mathrm{BH}$, Tang $\mathrm{ZY}$. Randomized controlled trial of screening for hepatocellular carcinoma. J Cancer Res Clin Oncol 2004;130:417-422. doi: 10.1007/s00432-004-0552-0.

[47] Yeh YP, Hu TH, Cho PY, Chen HH, Yen AM, Chen SL, et al. Evaluation of abdominal ultrasonography mass screening for hepatocellular carcinoma in Taiwan. Hepatology 2014;59:1840-1849. doi: 10.1002/hep.26703.

[48] American College of Radiology. Liver Reporting \& Data System. Available from: https://www.acr.org/Clinical-Resources/Reporting-and-Data-Systems/ LI-RADS.

[49] Choi JY, Lee JM, Sirlin CB. CT and MR imaging diagnosis and staging of hepatocellular carcinoma: part I. Development, growth, and spread: key pathologic and imaging aspects. Radiology 2014;272:635-654. doi: 10. 1148 /radiol.14132361.

[50] Takayama T, Makuuchi M, Hirohashi S, Sakamoto M, Okazaki N, Takayasu K, et al. Malignant transformation of adenomatous hyperplasia to hepatocellular carcinoma. Lancet 1990;336:1150-1153. doi: 10.1016/0140-6736 (90)92768-d.

[51] Kutami R, Nakashima Y, Nakashima O, Shiota K, Kojiro M. Pathomorphologic study on the mechanism of fatty change in small hepatocellular carcinoma of humans. J Hepatol 2000;33:282-289. doi: 10.1016/s0168-8278(00) 80369-4.

[52] Terada T, Kadoya M, Nakanuma Y, Matsui O. Iron-accumulating adenomatous hyperplastic nodule with malignant foci in the cirrhotic liver. Histopathologic, quantitative iron, and magnetic resonance imaging in vitro studies. Cancer 1990;65:1994-2000. doi: 10.1002/1097-0142 (19900501)65:9<1994::AID-CNCR2820650919>3.0.CO;2-B.

[53] Kogita S, Imai $Y$, Okada M, Kim T, Onishi H, Takamura M, et al. Gd-EOBDTPA-enhanced magnetic resonance images of hepatocellular carcinoma: correlation with histological grading and portal blood flow. Eur Radiol 2010; 20:2405-2413. doi: 10.1007/s00330-010-1812-9.

[54] Guo J, Seo Y, Ren S, Hong S, Lee D, Kim S, et al. Diagnostic performance of contrast-enhanced multidetector computed tomography and gadoxetic acid disodium-enhanced magnetic resonance imaging in detecting hepatocellular carcinoma: direct comparison and a meta-analysis. Abdom Radiol (NY) 2016:41:1960-1972. doi: 10.1007/s00261-016-0807-7.

[55] Burrel M, Llovet JM, Ayuso C, Iglesias C, Sala M, Miquel R, et al. MRI angiography is superior to helical CT for detection of HCC prior to liver transplantation: an explant correlation. Hepatology 2003;38:1034-1042. doi: 10. 1053/jhep.2003.50409.

[56] Kim CK, Lim JH, Lee WJ. Detection of hepatocellular carcinomas and dysplastic nodules in cirrhotic liver: accuracy of ultrasonography in transplant patients. J Ultrasound Med 2001;20:99-104. doi: 10.7863/jum.2001.20.2. 99.

[57] Roberts LR, Sirlin CB, Zaiem F, Almasri J, Prokop LJ, Heimbach JK, et al. Imaging for the diagnosis of hepatocellular carcinoma: A systematic review and meta-analysis. Hepatology 2018;67:401-421. doi: 10.1002/hep. 29487.

[58] Bolondi L, Cillo U, Colombo M, Craxì A, Farinati F, Giannini EG, et al. Position paper of the Italian Association for the Study of the Liver (AISF): the multidisciplinary clinical approach to hepatocellular carcinoma. Dig Liver Dis 2013;45:712-723. doi: 10.1016/j.dld.2013.01.012.

[59] Burak KW, Sherman M. Hepatocellular carcinoma: Consensus, controversies and future directions. A report from the Canadian Association for the Study of the Liver Hepatocellular Carcinoma Meeting. Can J Gastroenterol Hepatol 2015;29:178-184. doi: 10.1155/2015/824263.

[60] Omata M, Cheng AL, Kokudo N, Kudo M, Lee JM, Jia J, et al. Asia-Pacific clinical practice guidelines on the management of hepatocellular carcinoma: a 2017 update. Hepatol Int 2017;11:317-370. doi: 10.1007/s12072-0179799-9.

[61] Sangiovanni A, Manini MA, Iavarone M, Romeo R, Forzenigo LV, Fraquelli M, et al. The diagnostic and economic impact of contrast imaging techniques in the diagnosis of small hepatocellular carcinoma in cirrhosis. Gut 2010;59: 638-644. doi: 10.1136/gut.2009.187286.

[62] Silva MA, Hegab B, Hyde C, Guo B, Buckels JA, Mirza DF. Needle track seeding following biopsy of liver lesions in the diagnosis of hepatocellular cancer: a systematic review and meta-analysis. Gut 2008;57:1592-1596. doi: $10.1136 /$ gut.2008.149062.

[63] Kim TK, Lee KH, Jang HJ, Haider MA, Jacks LM, Menezes RJ, et al. Analysis of gadobenate dimeglumine-enhanced MR findings for characterizing small $(1-2-\mathrm{cm})$ hepatic nodules in patients at high risk for hepatocellular carcinoma. Radiology 2011;259:730-738. doi: 10.1148/radiol.11101549.

[64] Rimola J, Forner A, Tremosini S, Reig M, Vilana R, Bianchi L, et al. Non-invasive diagnosis of hepatocellular carcinoma $\leq 2 \mathrm{~cm}$ in cirrhosis. Diagnostic accuracy assessing fat, capsule and signal intensity at dynamic MRI. J Hepatol 2012;56:1317-1323. doi: 10.1016/j.jhep.2012.01.004.

[65] Sano K, Ichikawa T, Motosugi U, Sou H, Muhi AM, Matsuda M, et al. Imaging study of early hepatocellular carcinoma: usefulness of gadoxetic acidenhanced MR imaging. Radiology 2011;261:834-844. doi: 10.1148/radiol. 11101840.

[66] Jang HJ, Kim TK, Khalili K, Yazdi L, Menezes R, Park SH, et al. Characterization of 1-to 2 -cm liver nodules detected on hcc surveillance ultrasound according to the criteria of the American Association for the Study of Liver Disease: is quadriphasic CT necessary? AJR Am J Roentgenol 2013;201: 314-321. doi: 10.2214/AJR.12.9341.

[67] Ishigami K, Yoshimitsu K, Nishihara $Y$, Irie H, Asayama $Y$, Tajima T, et al. Hepatocellular carcinoma with a pseudocapsule on gadolinium-enhanced MR images: correlation with histopathologic findings. Radiology 2009; 250:435-443. doi: 10.1148/radiol.2501071702.

[68] Nakayama H, Enzan H, Yamamoto M, Miyazaki E, Yasui W. High molecular weight caldesmon positive stromal cells in the capsule of hepatocellular carcinomas. J Clin Pathol 2004;57:776-777. doi: 10.1136/jcp.2004. 016279.

[69] Shingaki N, Tamai H, Mori $Y$, Moribata K, Enomoto S, Deguchi H, et al. Serological and histological indices of hepatocellular carcinoma and tumor volume doubling time. Mol Clin Oncol 2013;1:977-981. doi: 10.3892/mco. 2013.186.

[70] Choi D, Mitchell DG, Verma SK, Bergin D, Navarro VJ, Malliah AB, et al. Hepatocellular carcinoma with indeterminate or false-negative findings at initial MR imaging: effect on eligibility for curative treatment initial observations. Radiology 2007;244:776-783. doi: 10.1148/radiol.2443061355.

[71] Chen L, Zhang L, Liang M, Bao J, Zhang J, Xia Y, et al. Magnetic resonance imaging with gadoxetic acid disodium for the detection of hepatocellular carcinoma: a meta-analysis of 18 studies. Acad Radiol 2014;21:16031613. doi: 10.1016/j.acra.2014.08.003.

[72] Cruite I, Tang A, Sirlin CB. Imaging-based diagnostic systems for hepatocellular carcinoma. AJR Am J Roentgenol 2013;201:41-55. doi: 10. 2214/AJR.13.10570.

[73] Park MS, Kim S, Patel J, Hajdu CH, Do RK, Mannelli L, et al. Hepatocellular carcinoma: detection with diffusion-weighted versus contrast-enhanced magnetic resonance imaging in pretransplant patients. Hepatology 2012; 56:140-148. doi: 10.1002/hep.25681.

[74] Hanna RF, Miloushev VZ, Tang A, Finklestone LA, Brejt SZ, Sandhu RS, et al. Comparative 13-year meta-analysis of the sensitivity and positive predictive value of ultrasound, CT, and MRI for detecting hepatocellular carcinoma. Abdom Radiol (NY) 2016;41:71-90. doi: 10.1007/s00261-0150592-8.

[75] Davenport MS, Viglianti BL, Al-Hawary MM, Caoili EM, Kaza RK, Liu PS, et al. Comparison of acute transient dyspnea after intravenous administration of gadoxetate disodium and gadobenate dimeglumine: effect on arterial phase image quality. Radiology 2013;266:452-461. doi: 10.1148/radiol. 12120826.

[76] Claudon M, Dietrich CF, Choi BI, Cosgrove DO, Kudo M, Nolsøe CP, et al. Guidelines and good clinical practice recommendations for Contrast Enhanced Ultrasound (CEUS) in the liver - update 2012: A WFUMBEFSUMB initiative in cooperation with representatives of AFSUMB, AIUM, ASUM, FLAUS and ICUS. Ultrasound Med Biol 2013;39:187-210. doi: 10. 1016/j.ultrasmedbio.2012.09.002.

[77] Wilson SR, Lyshchik A, Piscaglia F, Cosgrove D, Jang HJ, Sirlin C, et al. CEUS LI-RADS: algorithm, implementation, and key differences from CT/MRI. Abdom Radiol (NY) 2018;43:127-142. doi: 10.1007/s00261-017-1250-0.

[78] Guang $Y$, Xie L, Ding H, Cai A, Huang Y. Diagnosis value of focal liver lesions with SonoVue ${ }^{\circledR}$-enhanced ultrasound compared with contrast-enhanced computed tomography and contrast-enhanced MRI: a meta-analysis. J Cancer Res Clin Oncol 2011;137:1595-1605. doi: 10.1007/s00432011-1035-8.

[79] Yu H, Jang HJ, Kim TK, Khalili K, Williams R, Lueck G, et al. Pseudoenhancement within the local ablation zone of hepatic tumors due to a nonlinear artifact on contrast-enhanced ultrasound. AJR Am J Roentgenol 2010;194: 653-659. doi: 10.2214/AJR.09.3109.

[80] Miles KA. Tumour angiogenesis and its relation to contrast enhancement on computed tomography: a review. Eur J Radiol 1999;30:198-205. doi: 10. 1016/s0720-048x(99)00012-1.

[81] Miles KA, Lee TY, Goh V, Klotz E, Cuenod C, Bisdas S, et al. Current status and guidelines for the assessment of tumour vascular support with dynamic contrast-enhanced computed tomography. Eur Radiol 2012;22:14301441. doi: 10.1007/s00330-012-2379-4

[82] Ippolito D, Sironi S, Pozzi M, Antolini L, Invernizzi F, Ratti L, et al. Perfusion $\mathrm{CT}$ in cirrhotic patients with early stage hepatocellular carcinoma: assessment of tumor-related vascularization. Eur J Radiol 2010;73:148-152. doi: 10.1016/j.ejrad.2008.10.014

[83] Sahani DV, Holalkere NS, Mueller PR, Zhu AX. Advanced hepatocellular carcinoma: CT perfusion of liver and tumor tissue-initial experience. Radiology 2007;243:736-743. doi: 10.1148/radiol.2433052020. 
[84] Fischer MA, Kartalis N, Grigoriadis A, Loizou L, Stål P, Leidner B, et al. Perfusion computed tomography for detection of hepatocellular carcinoma in patients with liver cirrhosis. Eur Radiol 2015;25:3123-3132. doi: 10. 1007/s00330-015-3732-1.

[85] Borgheresi A, Gonzalez-Aguirre A, Brown KT, Getrajdman GI, Erinjeri JP, Covey $A$, et al. Does enhancement or perfusion on preprocedure CT predict outcomes after embolization of hepatocellular carcinoma? Acad Radiol 2018;25:1588-1594. doi: 10.1016/j.acra.2018.02.027.

[86] Nakamura Y, Kawaoka T, Higaki T, Fukumoto W, Honda Y, Iida M, et al. Hepatocellular carcinoma treated with sorafenib: Arterial tumor perfusion in dynamic contrast-enhanced CT as early imaging biomarkers for survival. Eur J Radiol 2018;98:41-49. doi: 10.1016/j.ejrad.2017.10.017.

[87] Ren Y, Fleischmann D, Foygel K, Molvin L, Lutz AM, Koong AC, et al. Antiangiogenic and radiation therapy: early effects on in vivo computed tomography perfusion parameters in human colon cancer xenografts in mice. Invest Radiol 2012;47:25-32. doi: 10.1097/RLI.0b013e31823a82f6.

[88] Wimmer T, Steiner J, Talakic E, Stauber R, Quehenberger F, Portugaller RH, et al. Computed tomography perfusion following transarterial chemoembolization of hepatocellular carcinoma: A feasibility study in the early period. J Comput Assist Tomogr 2017;41:708-712. doi: 10.1097/RCT. 0000000000000592.

[89] Mahnken AH, Klotz E, Schreiber S, Bruners P, Isfort P, Günther RW, et al. Volumetric arterial enhancement fraction predicts tumor recurrence after hepatic radiofrequency ablation of liver metastases: initial results. AJR Am J Roentgenol 2011;196:W573-W579. doi: 10.2214/AJR.10.4410.

[90] Goetti R, Reiner CS, Knuth A, Klotz E, Stenner F, Samaras P, et al. Quantitative perfusion analysis of malignant liver tumors: dynamic computed tomography and contrast-enhanced ultrasound. Invest Radiol 2012;47: 18-24. doi: 10.1097/RLI.0b013e318229ff0d.

[91] McCollough CH, Leng S, Yu L, Fletcher JG. Dual- and multi-energy CT: Principles, technical approaches, and clinical applications. Radiology 2015;276: 637-653. doi: 10.1148/radiol.2015142631.

[92] Davarpanah AH, Weinreb JC. The role of imaging in hepatocellular carcinoma: the present and future. J Clin Gastroenterol 2013;47 Suppl:S7S10. doi: 10.1097/MCG.0b013e31827f0d3d.

[93] Park JH, Kim SH, Park HS, Kim GH, Lee JY, Lee JM, et al. Added value of $80 \mathrm{kVp}$ images to averaged $120 \mathrm{kVp}$ images in the detection of hepatocellular carcinomas in liver transplantation candidates using dual-source dualenergy MDCT: results of JAFROC analysis. Eur J Radiol 2011;80:e76-e85. doi: 10.1016/j.ejrad.2010.08.018.

[94] Lv P, Lin XZ, Chen K, Gao J. Spectral CT in patients with small HCC: investigation of image quality and diagnostic accuracy. Eur Radiol 2012;22: 2117-2124. doi: 10.1007/s00330-012-2485-3.

[95] Mulé S, Pigneur F, Quelever R, Tenenhaus A, Baranes L, Richard P, et al. Can dual-energy CT replace perfusion CT for the functional evaluation of advanced hepatocellular carcinoma? Eur Radiol 2018;28:1977-1985. doi: 10.1007/s00330-017-5151-y.

[96] Ganeshan B, Miles KA. Quantifying tumour heterogeneity with CT. Cancer Imaging 2013;13:140-149. doi: 10.1102/1470-7330.2013.0015.

[97] Davnall F, Yip CS, Ljungqvist G, Selmi M, Ng F, Sanghera B, et al. Assessment of tumor heterogeneity: an emerging imaging tool for clinical practice? Insights Imaging 2012;3:573-589. doi: 10.1007/s13244-0120196-6.

[98] Hockel M, Schlenger K, Aral B, Mitze M, Schaffer U, Vaupel P. Association between tumor hypoxia and malignant progression in advanced cancer of the uterine cervix. Cancer Res 1996;56:4509-4515.

[99] Fu S, Chen S, Liang C, Liu Z, Zhu Y, Li Y, et al. Texture analysis of intermediate-advanced hepatocellular carcinoma: prognosis and patients' selection of transcatheter arterial chemoembolization and sorafenib. Oncotarget 2017;8:37855-37865. doi: 10.18632/oncotarget.13675.

[100] Zhou W, Zhang L, Wang K, Chen S, Wang G, Liu Z, et al. Malignancy characterization of hepatocellular carcinomas based on texture analysis of contrast-enhanced MR images. J Magn Reson Imaging 2017;45:1476-1484. doi: $10.1002 / j m r i .25454$

[101] Martín Noguerol T, Sánchez-González J, Martínez Barbero JP, García-Fiqueiras $\mathrm{R}$, Baleato-González S, Luna A. Clinical imaging of tumor metabolism with ${ }^{1} \mathrm{H}$ magnetic resonance spectroscopy. Magn Reson Imaging Clin N Am 2016;24: 57-86. doi: 10.1016/j.mric.2015.09.002.

[102] ter Voert EG, Heijmen L, van Laarhoven HW, Heerschap A. In vivo magnetic resonance spectroscopy of liver tumors and metastases. World J Gastroenterol 2011;17:5133-5149. doi: 10.3748/wjg.v17.i47.5133.

[103] Kuo YT, Li CW, Chen CY, Jao J, Wu DK, Liu GC. In vivo proton magnetic resonance spectroscopy of large focal hepatic lesions and metabolite change of hepatocellular carcinoma before and after transcatheter arterial chemoembolization using 3.0-T MR scanner. J Magn Reson Imaging 2004; 19:598-604. doi: 10.1002/jmri.20046.

[104] Bell JD, Cox IJ, Sargentoni J, Peden CJ, Menon DK, Foster CS, et al. A 31P and $1 \mathrm{H}-\mathrm{NMR}$ investigation in vitro of normal and abnormal human liver. Biochim Biophys Acta 1993;1225:71-77. doi: 10.1016/0925-4439(93) 90124-j.
[105] Qayyum A. MR spectroscopy of the liver: principles and clinical applications. Radiographics 2009;29:1653-1664. doi: 10.1148/rg.296095520.

[106] Shiratori Y, Imazeki F, Moriyama M, Yano M, Arakawa Y, Yokosuka O, et al. Histologic improvement of fibrosis in patients with hepatitis $C$ who have sustained response to interferon therapy. Ann Intern Med 2000;132:517524. doi: 10.7326/0003-4819-132-7-200004040-00002.

[107] Friedrich-Rust M, Ong MF, Martens S, Sarrazin C, Bojunga J, Zeuzem S, et al. Performance of transient elastography for the staging of liver fibrosis: a meta-analysis. Gastroenterology 2008;134:960-974. doi: 10.1053/j. gastro.2008.01.034.

[108] Jung KS, Kim SU, Ahn SH, Park YN, Kim DY, Park JY, et al. Risk assessment of hepatitis B virus-related hepatocellular carcinoma development using liver stiffness measurement (FibroScan). Hepatology 2011;53:885-894. doi: $10.1002 /$ hep. 24121 .

[109] Gerber L, Fitting D, Srikantharajah K, Weiler N, Kyriakidou G, Bojunga J, et al. Evaluation of 2D- shear wave elastography for characterisation of focal liver lesions. J Gastrointestin Liver Dis 2017;26:283-290. doi: 10. 15403/jgld.2014.1121.263.dsh.

[110] Venkatesh SK, Yin M, Ehman RL. Magnetic resonance elastography of liver: technique, analysis, and clinical applications. J Magn Reson Imaging 2013; 37:544-555. doi: 10.1002/jmri.23731.

[111] Venkatesh SK, Yin M, Glockner JF, Takahashi N, Araoz PA, Talwalkar JA, et al. MR elastography of liver tumors: preliminary results. AJR Am J Roentgenol 2008;190:1534-1540. doi: 10.2214/AJR.07.3123.

[112] Thompson SM, Wang J, Chandan VS, Glaser KJ, Roberts LR, Ehman RL, et al. MR elastography of hepatocellular carcinoma: Correlation of tumor stiffness with histopathology features-Preliminary findings. Magn Reson Imaging 2017;37:41-45. doi: 10.1016/j.mri.2016.11.005.

[113] Le Bihan D, Breton E, Lallemand D, Grenier P, Cabanis E, Laval-Jeantet M. MR imaging of intravoxel incoherent motions: application to diffusion and perfusion in neurologic disorders. Radiology 1986;161:401-407. doi: 10. 1148/radiology.161.2.3763909.

[114] Kele PG, van der Jagt EJ. Diffusion weighted imaging in the liver. World J Gastroenterol 2010;16:1567-1576. doi: 10.3748/wjg.v16.i13.1567.

[115] Agnello F, Ronot M, Valla DC, Sinkus R, Van Beers BE, Vilgrain V. High-bvalue diffusion-weighted MR imaging of benign hepatocellular lesions: quantitative and qualitative analysis. Radiology 2012;262:511-519. doi: 10.1148/radiol.11110922.

[116] Nasu K, Kuroki Y, Tsukamoto T, Nakajima H, Mori K, Minami M. Diffusionweighted imaging of surgically resected hepatocellular carcinoma: imaging characteristics and relationship among signal intensity, apparent diffusion coefficient, and histopathologic grade. AJR Am J Roentgenol 2009;193: 438-444. doi: 10.2214/AJR.08.1424.

[117] Woo S, Lee JM, Yoon JH, Joo I, Han JK, Choi BI. Intravoxel incoherent motion diffusion-weighted MR imaging of hepatocellular carcinoma: correlation with enhancement degree and histologic grade. Radiology 2014;270: 758-767. doi: 10.1148/radiol.13130444.

[118] Luo M, Zhang L, Jiang XH, Zhang WD. Intravoxel incoherent motion: application in differentiation of hepatocellular carcinoma and focal nodular hyperplasia. Diagn Interv Radiol 2017;23:263-271. doi: 10.5152/dir. 2017.16595.

[119] Guo Z, Zhang Q, Li X, Jing Z. Intravoxel incoherent motion diffusion weighted MR imaging for monitoring the instantly therapeutic efficacy of radiofrequency ablation in rabbit VX2 Tumors without evident links between conventional perfusion weighted images. PLoS One 2015;10: e0127964. doi: 10.1371/journal.pone.0127964.

[120] Taylor AJ, Salerno M, Dharmakumar R, Jerosch-Herold M. T1 mapping: Basic techniques and clinical applications. JACC Cardiovasc Imaging 2016;9:67-81. doi: 10.1016/j.jcmg.2015.11.005.

[121] Ding Y, Rao SX, Meng T, Chen C, Li R, Zeng MS. Usefulness of T1 mapping on Gd-EOB-DTPA-enhanced MR imaging in assessment of non-alcoholic fatty liver disease. Eur Radiol 2014;24:959-966. doi: 10.1007/s00330-0143096-y.

[122] Katsube T, Okada M, Kumano S, Imaoka I, Kagawa Y, Hori M, et al. Estimation of liver function using T2* mapping on gadolinium ethoxybenzyl diethylenetriamine pentaacetic acid enhanced magnetic resonance imaging. Eur J Radiol 2012;81:1460-1464. doi: 10.1016/j.ejrad.2011. 03.073.

[123] Pan S, Wang XQ, Guo QY. Quantitative assessment of hepatic fibrosis in chronic hepatitis B and C: T1 mapping on Gd-EOB-DTPA-enhanced liver magnetic resonance imaging. World J Gastroenterol 2018;24:2024-2035. doi: 10.3748/wjg.v24.i18.2024.

[124] Yoshimura N, Saito K, Saguchi T, Funatsu T, Araki Y, Akata S, et al. Distinguishing hepatic hemangiomas from metastatic tumors using T1 mapping on gadoxetic-acid-enhanced MRI. Magn Reson Imaging 2013;31:23-27. doi: 10.1016/j.mri.2012.06.026.

[125] Peng Z, Li C, Chan T, Cai H, Luo Y, Dong Z, et al. Quantitative evaluation of Gd-EOB-DTPA uptake in focal liver lesions by using T1 mapping: differences between hepatocellular carcinoma, hepatic focal nodular hyperplasia and 
Navin P.J. et al: Hepatocellular carcinoma- advances in imaging

cavernous hemangioma. Oncotarget 2017;8:65435-65444. doi: 10 . 18632/oncotarget.18918.

[126] Welch JS, Westervelt P, Ding L, Larson DE, KIco JM, Kulkarni S, et al. Use of whole-genome sequencing to diagnose a cryptic fusion oncogene. JAMA 2011;305:1577-1584. doi: 10.1001/jama.2011.497.

[127] Segal E, Sirlin CB, Ooi C, Adler AS, Gollub J, Chen X, et al. Decoding global gene expression programs in liver cancer by noninvasive imaging. Nat Biotechnol 2007;25:675-680. doi: 10.1038/nbt1306.
[128] Kuo MD, Gollub J, Sirlin CB, Ooi C, Chen X. Radiogenomic analysis to identify imaging phenotypes associated with drug response gene expression programs in hepatocellular carcinoma. J Vasc Interv Radiol 2007;18:821831. doi: 10.1016/j.jvir.2007.04.031.

[129] Sørensen M, Frisch K, Bender D, Keiding S. The potential use of 2-[ $\left.{ }^{1} \square F\right]$ fluoro-2-deoxy-D-galactose as a PET/CT tracer for detection of hepatocellular carcinoma. Eur J Nucl Med Mol Imaging 2011;38:1723-1731. doi: 10. 1007/s00259-011-1831-z. 